\title{
UNA DÉCADA DE TURISMO SIN FRONTERAS. EL CASO DE LA REGIÓN DUERO/ DOURO, EL TURISMO FLUVIAL Y LA DIVERSIDAD TURÍSTICA
}

\author{
Elena Ruiz Romero de la Cruz* \\ Universidad de Málaga \\ https://orcid.org/0000-0003-1916-2424 \\ Elena Cruz Ruiz** \\ Universidad de Málaga \\ https://orcid.org/0000-0002-8334-3900 \\ Gorka Zamarreño Aramendia** \\ Universidad de Málaga \\ https://orcid.org/0000-0003-1568-4540
}

\section{RESUMEN}

La incorporación de España y Portugal a la Comunidad Europea ha impulsado la cooperación transfronteriza y el turismo a ambos lados de la frontera luso española. Nuestro análisis se ciñe a la Región Duero/Douro con el río Duero y el turismo fluvial de referente, un nicho de mercado que ha progresado en los últimos años, revalorizando la diversidad turística existente a través de las actividades acuáticas y el turismo de cruceros. Los recursos y una naturaleza protegida han permitido a ambos lados de la frontera, afianzar el sector turístico ligado al Duero y al Douro, intensificándose en el último lustro la actividad fluvial, reunida al turismo enológico y a los espacios naturales protegidos.

Palabras clave: Turismo de frontera; turismo transfronterizo; productos y recursos turísticos; cruceros fluviales; río Duero/Douro; UNESCO.

Fecha de recepción: 28 de junio de 2018.

Fecha de aceptación: 29 de abril de 2019.

* Facultad de Ciencias Económicas y Empresariales. Universidad de Málaga. Plaza de El Ejido s/n. 29013 MÁLAGA (España).E-mail: emruiz@uma.es

** Facultad de Comercio y Gestión. Universidad de Málaga. Av. Francisco Trujillo Villanueva, 1, 29071 MÁLAGA (España).E-mail: ecruz@uma.es, gzama@uma.es 


\section{A decade without border tourism. The case of the Douro river region and the fluvial tourism}

\section{ABSTRACT}

The membership of Spain and Portugal to the European Union has encouraged cross-border cooperation, promoting the diversification of the tourism in both sides of the Luso-Spanish border. Our analysis takes as a reference Duero/Douro region and the Douro River, this fluvial tourism has revalued cultural, wine and heritage tourism with water activities and cruises, reinforcing the existing tourist diversity. The resource management has allowed on both sides of the border, strengthen the tourism sector linked to the Douro and the Douro, intensifying in the last five years the fluvial activity, gathered around the wine tourism and the natural spaces.

Keywords: Border tourism; cross-border tourism; tourism products and resources; river cruises; Douro River / Douro; UNESCO.

\section{INTRODUCCIÓN}

Las estrategias de desarrollo de la región Duero, a ambos lados de la frontera luso española, han puesto en marcha un modelo de crecimiento, en el que el impulso turístico es vital, muy especialmente tras la incorporación de España y Portugal a la Unión Europea.

La distinción entre turismo transfronterizo y de frontera es un tratamiento clásico de los horizontes compartidos entre países limítrofes, conformando el primero un territorio mucho mayor que la propia frontera administrativa (borderland) (Jurado Almonte y Pazos García, 2018).

El término turismo sin fronteras se ha acuñado para el análisis de la actividad turística entre la propia frontera y los territorios que van más allá de la misma. Es una línea de investigación necesaria, sobre la base de las nuevas identidades transfronterizas emergentes, necesitadas de estudios que muestren la integración entre territorios lindantes (Mansvelt Beck y Hortelano Mínguez, 2016, Jorge Filipa et al., 2017).

Los tratados de cooperación entre España y Portugal han ido fraguando en los últimos años nuevas inquietudes y vías de entendimiento (Sereno, 2011, Manero Miguel, 2102, Calderón Vázquez, 2015), unas relaciones transfronterizas esenciales para ambos países (Rocha Medeiros, 2009, López Trigal, 2012, Canto García, 2016).

Los principales acuerdos internacionales tuvieron como prioridad los aprovechamientos hidroeléctricos fronterizos, más tarde se evolucionaría hacia el estudio de políticas medioambientales del caudal del río, que nace en España y muere en Oporto (Rossoto Ioris, 2008, 2012), colaborando al progreso de las actividades acuáticas y cruceros fluviales, dando paso a los nuevos usos de los recursos hídricos (García González, 2004, 245-246, Oliveira Moreira y Pinto Dos Santos, 2010).

La búsqueda de modelos de desarrollo para España y Portugal ha avanzado en el tiempo, si comparamos estudios de inicios del siglo XXI (Romero, 2005, Cristóvão, A, 2006) y trabajos más recientes (Almeida García, 2012, Almeida Mendonça, 2012). Observamos que el balance de actuaciones se intensifica en la última década (Hortelano 
Mínguez, 2013), desde una frontera "en transición” a una cooperación institucional, en pos del desarrollo de amplias zonas deprimidas de interior (Calderón Vázquez, 2010, 2017), llevándose a cabo una política turística con implicación de entidades públicas de ámbito nacional, regional y local (Rodríguez et al., 2018).

El turismo entre países limítrofes rescata del olvido la importancia que tiene en los nuevos retos turísticos la vuelta a lo "auténtico", si bien, es una larga historia participada por la misma frontera (García, 2012, Ribeiro Costa, 2013, Ribeiro Costa y Azevedo, 2015), motivo de atracción en sí misma (Trillo Santamaría y Lois González, 2011, Moral Cuadra et al., 2016) y un lugar de paso en el periplo, que puede revitalizar el conjunto del sector turístico (Hernández Ramírez, 2017).

La riqueza patrimonial y paisajística de las zonas fronterizas entre España y Portugal es una realidad analizada (Palmero Piñeiro y Pazos Otón, 2008, Trillo Santamaría, 2010, Martín Jiménez, 2016), más en la zona fronteriza que a lo largo del cauce del Duero, si bien, algunos trabajos ya plantearon el estudio global del río bajo una perspectiva turística (Hortelano Mínguez, 2004).

Otros cauces fluviales que cruzan la frontera de España son las dos grandes cuencas hidrográficas de Extremadura, Tajo y Guadiana que, como en el caso que se analiza, penetran en Portugal (Campesino Fernández, 2016). Precisamente el Proyecto de Cooperación Tajo/Tejo Internacional ambiciona la puesta en marcha de diferentes productos turísticos, donde la cultura, la gastronomía y las actividades deportivas como el senderismo, contribuyen al progreso del entorno (Sánchez Rivero, 2014).

Los ámbitos territoriales y los escenarios fluviales de la Raya Ibérica, con el río como protagonista van a generar nuevas oportunidades de negocio, sobre el que construir políticas de desarrollo más eficientes (Campesino Fernández, (Dir.), 2013, 2014, Campesino Fernández y Jurado Almonte, (Coord.), 2014, Campesino Fernández, 2016), tratando las diversas temáticas del Duero/Douro como puente turístico entre España y Portugal (Cruz Ruiz et al., 2018). ${ }^{1}$

Iniciativas dignas de mención son las llevadas a cabo por el Centro de Estudios Ibéricos, plataforma que desde 2001 trabaja en pos de un mayor conocimiento de la economía de la frontera hispano lusa. Mencionamos el proyecto "Aldeias Históricas", de la Comisión y Coordinación de la Región Centro (CCRC), que se conforma para favorecer su proyección turística (Kastenholz et al., 2012), abriéndose en el último lustro una línea de investigación básica para el entendimiento del proceso de revalorización de estos espacios (Campesino Fernández, (Dir.), 2013 y 2014).

La región Duero puede tratarse bajo múltiples puntos de vista, en términos de población, economía y territorio (Hortelano Mínguez, 2013, 2014a, 2014b, Martín Jiménez y Hortelano Mínguez, 2017), como contraste entre áreas rayanas muy dinámicas y algunas de las comarcas más regresivas de la Península Ibérica (Lois González y Carballo Lomba, 2015). La perspectiva geográfica es abordada en los manuscritos recogidos en Guichard, López Trigal y Marrou (Coords.), (2000) y recientemente, entre otros, en Lois

1 Será en 2002 cuando en el III Encontro Relações Portugal-Espanha O Vale do Douro no Âmbito das Regiões Europeias, celebrado en Zamora, se analicen y recojan las iniciativas propuestas, contemplándose numerosas casuísticas de actuación. Los encuentros que precedieron al mencionado favorecieron las bases de las relaciones entre España y Portugal. 
González et al., (2015). Y ya sobre la base regional se ciñen los trabajos de Sánchez Martín, (2013) y Salcedo Hernández, (2013).

En cualquier caso, el estudio de los nuevos nichos de mercado es imprescindible para el desarrollo de los territorios abocados a un proceso de desfronterización (López Trigal, 2016: 181). La nueva industria turística basada en el río se constituirá en un aliciente "innovador" para la explotación de los recursos disponibles del paisaje, fauna y flora y la potenciación del turismo del vino (Oliveira Moreira y Pinto Dos Santos, 2010).

El análisis de la región parte de los segmentos y microproductos existentes en este marco de referencia fluvial, incidiendo en los vínculos que genera el propio río a su paso por España y Portugal, en una estrategia de comunicación integradora para la promoción de la marca "Douro" (Ribeiro Costa, 2013, Jorge Filipa et al., 2017), favoreciendo las denominaciones de origen que amparan la calidad de los vinos elaborados en su ribera (Ruiz Romero de la Cruz et al., 2017).

Los trabajos sobre el turismo fluvial y las actividades acuáticas en España son escasos, quizás porque son un segmento turístico reciente y en el caso que nos ocupa, por ser en territorio luso donde principalmente ha alcanzado cotas significativas de impacto, (Nunes et al., 2016, Campesino Fernández, 2016, Carvalho Teles, 2012, Nuno Torres Senra, 2014, Amorín et al., 2012a, Cruz Ruiz et al., 2018).

Nuestro análisis dejará de manifiesto el interés que posee el estudio del turismo fluvial en la Península Ibérica y en la región Douro. A nivel internacional, como ejemplo del poder de atracción turística de los ríos, que fluyen entre países que comparten sus cauces o como dinamizadores del territorio (Buckley et al., 2018, Mohd Nasir y Hanafiah, 2017, Kovacic et al., 2017).

La investigación partirá de la bibliografía existente, tomando los datos y cifras de la Administração dos Portos do Douro, Leixões e Viana do Castelo (APDL), así como la información de Europarques, sociedad que gestiona esta actividad en el ámbito español.

Este estudio tratará de dar respuesta a ciertos interrogantes: ¿Qué recursos provee el entorno del río Duero/Douro a nivel turístico a ambos lados de la frontera luso española?, ¿Cuáles son los productos náuticos que impulsan el desarrollo? ¿Qué evolución ha tenido el turismo de cruceros?, todo ello teniendo en cuenta las limitaciones que poseen las fuentes disponibles.

\section{RECURSOS TURÍSTICOS RAYANOS Y TRANSFRONTERIZOS EN LA REGIÓN DUERO/DOURO}

El río Duero/Douro está unido al progreso turístico de las zonas donde fluye, generando sinergias que retroalimentan el desarrollo a través del turismo fluvial, determinantes en los modelos de gestión (Navarro, 2015), potenciando los recursos que, tanto en el lado portugués como en el español otorgan identidad a unos pueblos, que han vivido a lo largo de la historia "compartiendo" a veces pobreza y en otros momentos progreso.

El trazado de la frontera luso española data de 1267, y una de sus singularidades es su gran amplitud, atravesando las unidades paisajísticas más representativas del occidente peninsular (Medina García, 2006, Elizaincín, 2006), vislumbrándose cauces fluviales de 
gran interés para el turismo, pues fluyen a través de montañas y valles de gran valor paisajístico, Miño, Tajo, Guadiana y el Duero son los más representativos.

En la Figura 1 se ha plasmado la diversidad turística existente, sobre la base de dos grandes pilares, por un lado, Cultura, Arte y Patrimonio y, por otro lado, Naturaleza, especialmente los espacios protegidos, que permiten y animan el llamado turismo activo, generando idóneas condiciones para el binomio deporte-turismo (Hortelano Mínguez, 2014b: 78, 2015: 259).

Un itinerario cultural promueve el turismo y colabora a la desestacionalización, elementos contemplados tanto desde la esfera pública como de la privada (De Uña-Álvarez et al., 2017). El turismo monumental y de museos se afianza en los últimos años favorecido por la UNESCO, en donde se encuentran los definidos como Bienes de Interés Cultural (BIC), acercando al turista a la cultura lugareña y a su historia (Hortelano Mínguez, 2015: 253-254). En los últimos tiempos, el conjunto de posibilidades se materializa en la diversidad de rutas puestas en marcha, recientemente recopiladas y analizadas (Hortelano Mínguez y Martín Jiménez, 2017), en una oferta cultural compartida (Da Costa Pereira y Pereiro 2014, Pereiro 2016, Trillo y Lois, 2011).

El marco religioso tiene una especial consideración en lo que concierne al Camino de Santiago portugués (Sotelo Navalpotro et al., 2016) y una relación con los monumentos que pueden ser catalogados dentro de este apartado (Morales Fernández y Pérez Naranjo, 2010). Las numerosas ermitas, monasterios y santuarios que los peregrinos visitan a un lado y otro de frontera, determinan un turismo que crece en cifras, gracias a las iniciativas institucionales (López Trigal, 2016: 194).

Las romerías, fiestas de interés turístico y los eventos cada vez son más valorados, contribuyendo al desarrollo de las localidades rayanas (Hortelano Mínguez, 2015, Martín Jiménez y Hortelano Mínguez, 2017).

Además, en la propia frontera debe mencionarse el interés turístico que despierta el recuerdo del contrabando o "descamino", que en su momento conformó una singular forma de "economía sumergida" (Hortelano Mínguez, 2015: 257-258, Cruz Sagredo, 2010, Calderón Vázquez, 2015).

El turismo gastronómico adquiere mayor notoriedad, al permitir redescubrir el valor de las tradiciones culinarias, convirtiéndose en otro elemento catalizador de voluntades de ocio en el ámbito fronterizo y transfronterizo (Cristóvão et al., 2008), reuniendo en numerosas ocasiones la tradición culinaria local y los productos fluviales (Amorín et al., 2012a).

Río, vino y cultura representan un conjunto de oportunidades, donde el capítulo enológico pasa de ser un mero recurso vinculado al sector primario, a referencia de ciertos destinos turísticos (Inácio, 2010), relacionando el turismo fluvial y las subregiones tipificadas por la singularidad de sus vinos. El denominado Alto Douro Vinhateiro otorga una nueva dimensión del desarrollo agrícola, por sus potenciales vínculos con el turismo y su estrecha relación con el terroir (Rebelo y Caldas, 2013, Guedes y Joukes, 2016), vinculando el Douro a los vinos (Nuno Torres Senra, 2014, Amorín et al., 2012a, Rebelo et al., 2014).

Una oferta que ha ido densificándose, gracias al valor de los recursos de la región y a la clasificación por la UNESCO de Patrimonio de la Humanidad de ciertos ámbitos (Fernandes de Sousa, 2013). Los escenarios paisajísticos y los elementos del patrimonio 
material e inmaterial protegidos favorecen el progreso económico (Hortelano Mínguez, 2013, 2014, 2015), colaborando la cultura al desarrollo sostenible de los territorios.

La naturaleza puede generar actividad turística si se acompaña de políticas que exploten los recursos naturales, cuyos excepcionales espacios muestran la fauna y flora del lugar, ejerciendo un poder de atracción turística indiscutible (López Trigal, 2016). La observación de la naturaleza en "estado puro", los encantos de la berrea y el avistamiento de las aves se han convertido en recursos turísticos de primer orden (Hortelano Mínguez, 2015: 260). Actividades que abren el abanico de posibilidades al desarrollo del turismo rural en la región Douro (De Jesús Pato, 2016).

La sociedad actual valora la salud y el bienestar, siendo los balnearios y termas referentes turísticos muy bien considerados (Pardellas et al., 2003, Figueroa Dorrego et al., 2014). De igual modo, tiene en cuenta la actividad geoturística, localizada en el Lago de Sanabria y en Arribes del Duero, permitiendo una interesante labor didáctica (Hortelano Mínguez, 2014), afianzando el turismo en conjunción con la naturaleza (Preto y Alencoão, 2005).

\section{Figura 1 \\ RECURSOS Y DIVERSIDAD TURÍSTICA EN EL ENTORNO DEL RÍO DUERO/DOURO}

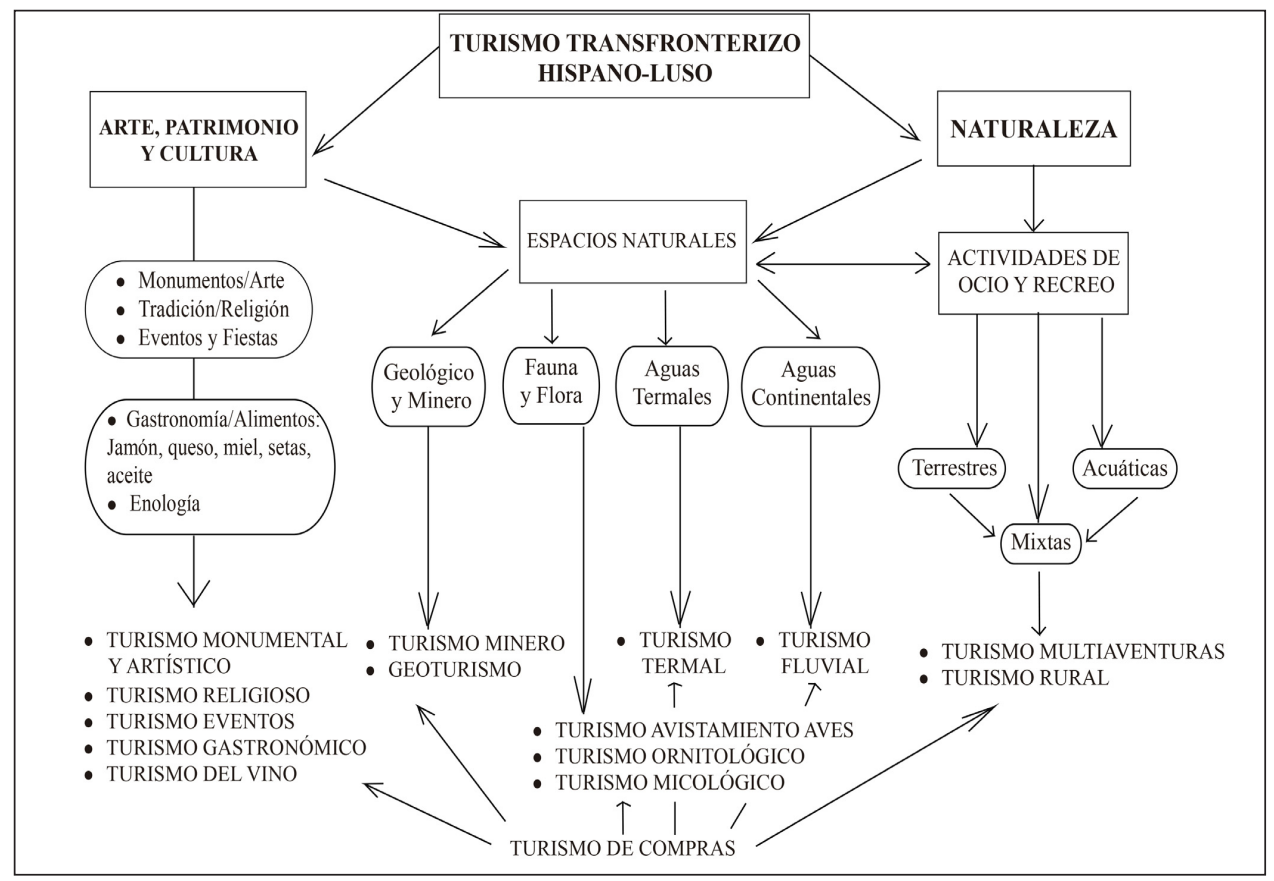

Fuente: Elaboración propia de los autores.

En el umbral del siglo XXI surgen iniciativas académicas e institucionales, ya en el marco de la Unión Europea, a fin de que los objetivos del progreso económico se alcancen 
en un medio natural, marcado por las sierras, penillanuras y profundos valles esculpidos por el Duero y sus afluentes (Hortelano Mínguez, 2015: 250, López Trigal, 2016).

El turismo activo adquiere todas sus modalidades en estos territorios, ya sean terrestres con recorridos a pie y en bicicleta, o actividades de recreo acuáticas en deportes como el kayak o el piragüismo, la vela, el ala delta y el vuelo sin motor, practicados por turistas que buscan en las aventuras la principal motivación del viaje (Hortelano Mínguez, 2016: 262-263). ${ }^{2}$

El turismo de compras está relacionado con todos los recursos turísticos, representando un atractivo añadido a cualquiera de los nichos de mercado existentes, revitalizando mercadillos y localidades vinculadas a productos de la "región", tales como jamones, miel, castañas y aceites entre otros.

La raya comercial se debate en los últimos tiempos entre el progreso de los mercados tradicionales y los centros comerciales, afianzando un turismo de compras en numerosas ciudades como Miranda do Douro, Vilar Formoso, Moura, Tui, etc. (López Trigal, 2016: 189-190).

\section{RÍO, FRONTERA, VINO Y NATURALEZA. EL CASO DUERO/DOURO}

El Duero fluye a lo largo de $895 \mathrm{kms}$, de los cuales 609 discurren por territorio español, 107 por el territorio fronterizo entre España y Portugal y los últimos 179 por tierras portuguesas, desde la desembocadura en el océano Atlántico hasta Barca d'Alva en la frontera con España. El desnivel que debe salvarse es de 125 metros, vencido por 5 esclusas de navegación, Crestuma, Carrapatelo, Régua, Valeira y Pocinho, instaladas estratégicamente en uno de los extremos del río facilitando el turismo fluvial (APDL, Via Navegável do Douro, 2018).

Los muelles para embarcaciones turísticas y de recreo han favorecido el crecimiento de las actividades acuáticas, con puntos de embarque en Vila Nova de Gaia o Porto, Peso da Régua, Pinhão, Pocinho y Barca d'Alva, en los que la ruta del vino discurre paralela, en el tramo navegable entre Porto y Barca d'Alva, a menudo con la contemplación de una naturaleza singular.

\subsection{El turismo fluvial y los espacios naturales en la Raya Ibérica y su proximidad}

La explotación de los recursos a ambos lados de la frontera hispano lusa ha posibilitado un desarrollo turístico de diferente significación, sobre la base de la Red de Espacios Naturales, donde se encuentran los Parques Naturales Lago de Sanabria y Alrededores, Arribes del Duero y otros espacios adyacentes y el Parque do Douro Internacional.

Este conjunto de espacios protegidos españoles y portugueses fue declarado por UNESCO en 2015 Reserva de la Biosfera Transfronteriza, de este modo, la Meseta Ibérica es ya la más extensa de la Península, con 1.132.606 has, de las cuales 475.241 has corresponden a territorio español. ${ }^{3}$ Un espacio natural que afecta a las provincias de Salamanca y Zamora,

2 Consultar https://www.zamoranatural.com/rio-douro-portugal/.

3 El área seleccionada incluye 108 municipios españoles. En Zamora se encontrarían 79, en Salamanca 29 y 17 concelhos de Portugal de las subcomarcas de Terra Quente y Terra Fria y Douro Superior. Ver Hortelano 


\section{Mapa 1}

\section{PARQUE NATURAL LOS ARRIBES DEL DUERO Y DOURO INTERNACIONAL}

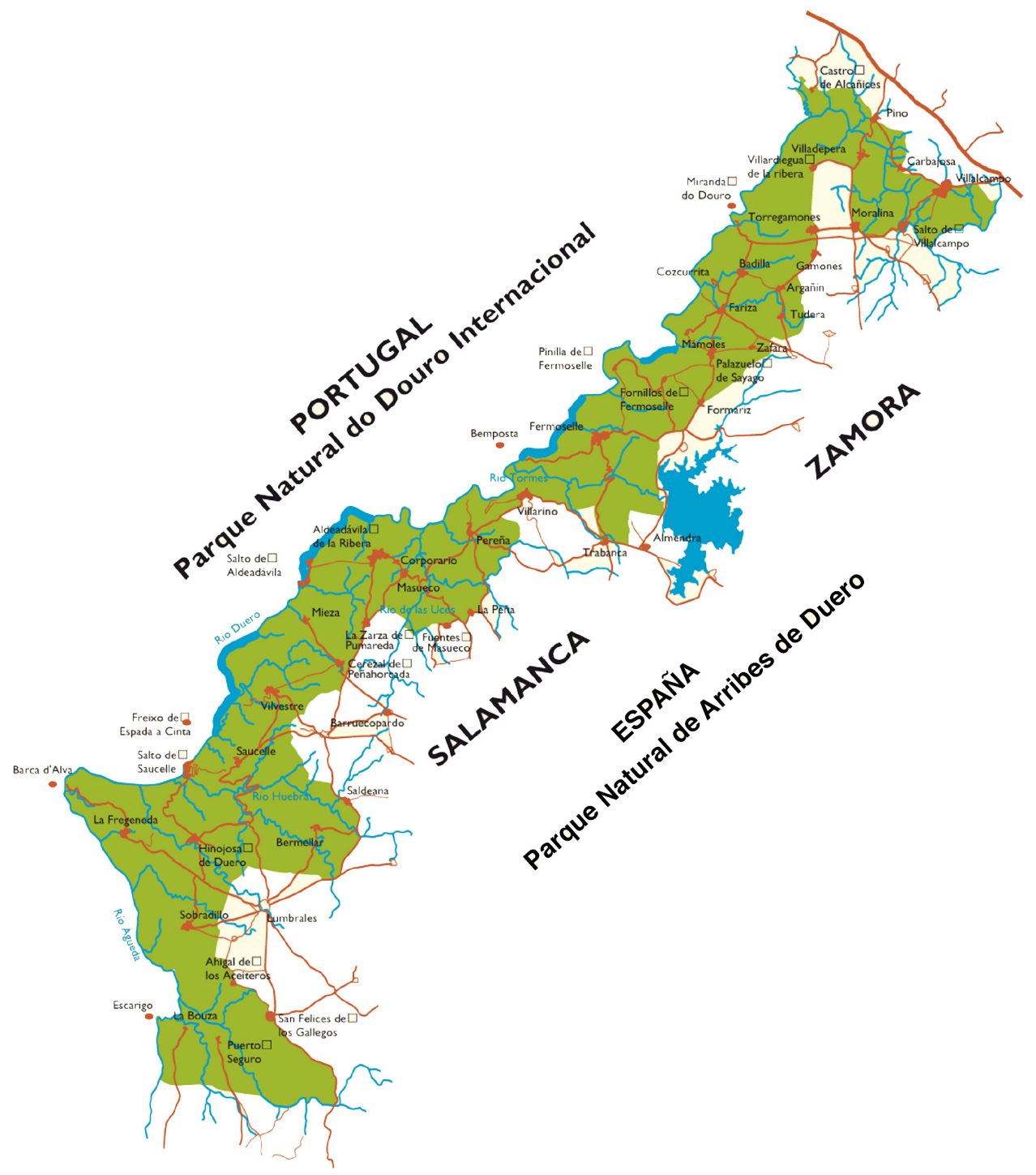

Fuente: www.tesosriberas.wordpres.com. Modificado por los autores. 
y al otro lado de La Raya ocupa las comarcas de Terra Quente y Terra Fria de la región de Trás-os-Montes, extendiéndose a un total de 87 Municipios, de los cuales 12 se encuentran en Portugal y 75 en España: 27 en Salamanca y 48 en Zamora (BOE-A-2015-9446).

Además, goza de la calificación de espacios protegidos e integrados en la Red Natura 2000 y ello permite el reconocimiento de Zona de Especial Protección de Aves (ZEPA) y Lugar de Interés Comunitario (LIC), reforzando la actividad turística ligada a esa zona (Hortelano Mínguez, 2015).

\section{Figura 2}

\section{ACTIVIDADES TURÍSTICAS Y EL TURISMO FLUVIAL EN PARQUES Y ESPACIOS NATURALES RÍO DUERO/DOURO}

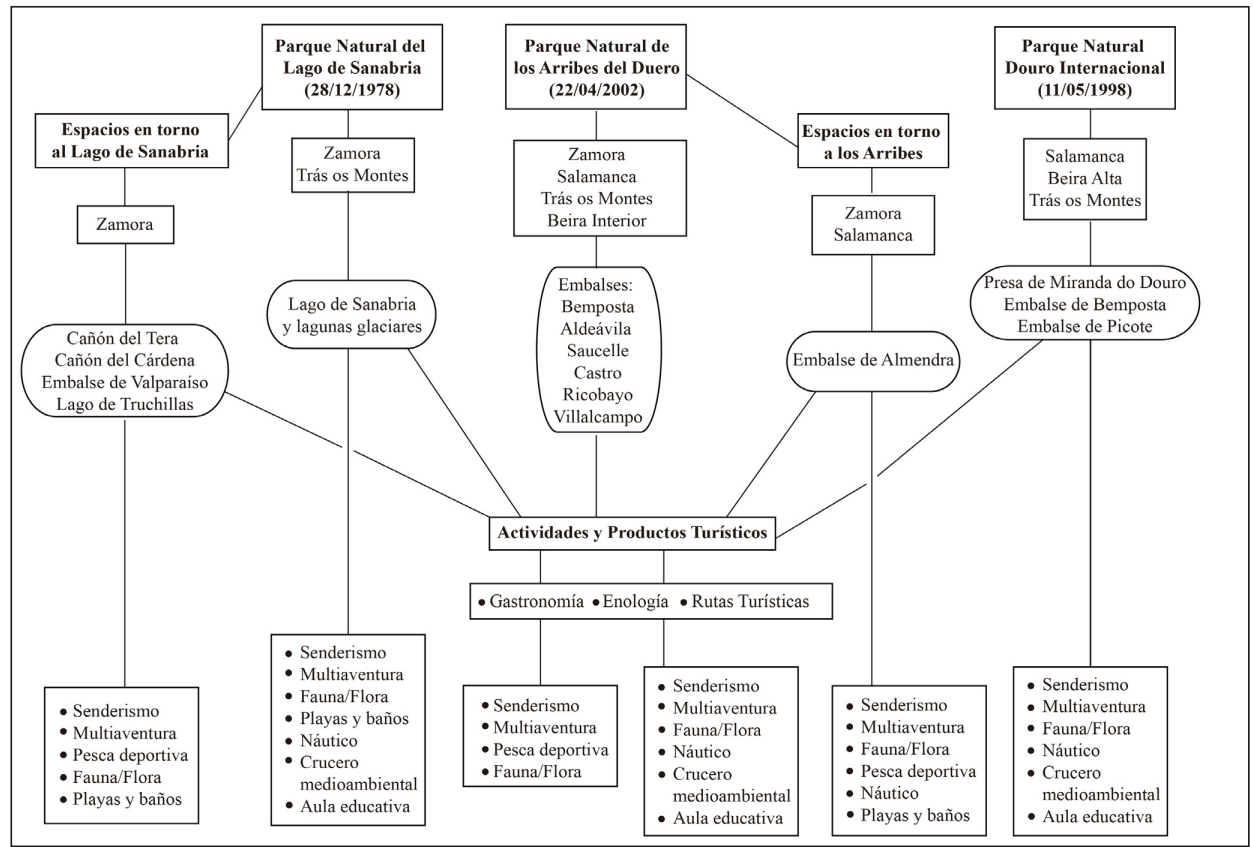

Fuente: Elaboración propia de los autores.

La Figura 2 muestra una clasificación de las actividades que tienen lugar en los espacios naturales protegidos o nó, pero de gran significación, así como las provincias donde se encuentran las láminas de agua, que permiten trazar una oferta turística ligada al turismo fluvial. Se ha elaborado teniendo en cuenta los trabajos de especialistas en turismo de frontera y transfronterizo (Campesino Fernández, 2016, Hortelano Mínguez, 2014, 2015, López Trigal, 2016) y el conjunto de páginas web que promocionan la riqueza paisajista del entorno Duero/Douro, tanto institucionales como de carácter empresarial.

Mínguez, L. A. (2015): "Patrimonio territorial y turismo en la «raya» de Castilla y León: la atracción de los paisajes y la puesta en valor de los recursos", Cuadernos de Turismo n 36, p. 251. 
La naturaleza ha obrado sobre el territorio unos tajos profundos en los que discurre el Duero y los afluentes, rodeados de una vegetación en donde habitan numerosas especies de aves, propiciando nichos de mercado aprovechando el turismo fluvial (Hortelano Mínguez y Martín Jiménez, 2017: 169).

Los Arribes fue declarado Parque Natural el 11 de abril de 2002 y el Parque Natural do Douro International obtuvo la clasificación el 11 de mayo de 1998. Ambos son limítrofes de un escenario fluvial, desarrollando un turismo bajo los principios de la sostenibilidad, con amplios beneficios económicos, ambientales y sociales y repercusiones para toda la región, gracias a su vasto patrimonio natural y cultural (Castro y Fernandes, 2007), de claro interés para el desarrollo del turismo rural, analizado ya a fines del siglo XX por Hortelano Mínguez, (1996).

La generación de embalses en el cauce del río ha ido forjando sinergias entre la naturaleza y la proyección turística de pueblos y localidades, especialmente en territorio español, ligadas a este hábitat natural, por lo que el senderismo, los deportes y multiaventuras, la fauna y la flora del lugar se constituyen en atractivos, originando la proliferación de rutas turísticas y una gastronomía y enología que han sido señas de identidad de ese "terroir", convirtiéndolos en destinos "únicos".

El Parque Natural de Sanabria promociona actividades de educación e interpretación ambiental a través de los cruceros, buscando un modelo de turismo sostenible (Guillén Oterino, 2015, Geraldes et al., 2017), un caso muy específico, pues representa el mayor lago glaciar de la Península Ibérica declarado desde 2015 reserva de la UNESCO. ${ }^{4}$

El Parque Natural Arribes del Duero ocupa una superficie de 106.105 has, perteneciente a las provincias de Zamora y Salamanca, de las que Fermoselle y Aldeadávila de la Ribera son sus capitales respectivas. En el embalse de Aldeadávila de la Ribera se ofertan itinerarios con la singular contemplación de la naturaleza y una flora y fauna autóctona. El embalse de Saucelle es atractivo turístico gracias a la observación del paisaje observado a ambos lados de la frontera, producto comercializado a través de La Sociedad Transfronteriza Congida, programando recorridos fluviales con excursiones de unas 2 horas de duración, mostrando los cortados hasta el paraje de La Code (Mieza), para regresar de nuevo al punto de partida. Entre la playa de Congida y La Code Mieza, pasando por la zona de la Barca de Vilvestre, se navegará entre el Douro Internacional y Arribes del Duero. 5

Los cruceros y el barranquismo son dos de las propuestas desarrolladas en Arribes. El punto de inicio de estos paseos y cruceros por el Duero es el embarcadero de Vega Terrón en La Fregeneda, ofertando en fines de semana recorridos de ida y vuelta en torno a las 3 horas, con el atractivo de la naturaleza en las provincias de Zamora, Salamanca y Portugal. Será en Miranda do Douro, en el Parque Natural do Douro International, el punto de embarque de sus cruceros, de extensión algo menor que en la zona española, pues dispone de 86.500 has, siendo considerada una de las grandes áreas protegidas de Europa. ${ }^{6}$

4 Ver otros elementos de interés en las siguientes páginas: www.turismosanabria.es/lago_sanabria.html. www.patrimonionatural.org/espacios.../parque-natural-lago-de-sanabria-y-alrededores.

5 Consultar www.losarribesdelduero.com/aldeadavila-de-la-ribera.

6 Pueden verse otros aspectos de interés en: www.vivelasarribes.es. 
El embalse de Miranda do Douro ofrece un crucero ambiental por el Parque Natural y otras actividades complementarias, en el que la fauna y la riqueza gastronómica reportan un atractivo añadido.

De igual modo, en los embalses de Bemposta y Picote el recorrido se efectúa por el Parque Natural do Douro Internacional y el recurso turístico por excelencia sigue siendo una naturaleza única, que se descubre en las travesías del Barco Arribas, recorriendo durante unas tres horas el paisaje entre la presa de Bemposta y la de Picote, con el objetivo de observar la naturaleza, especialmente la fauna (águila real, buitres, ánades, cigüeña negra, etc.) y la vegetación propia de Arribes. ${ }^{7}$

Finalmente, destacar que la actividad crucerística en la Raya Ibérica se establece en torno a la Estación Biológica Internacional del Duero (EBI), con competencias sobre tres parques naturales: Arribes del Duero, Lago de Sanabria y Douro Internacional.

La Estación tiene sus orígenes en 1993, cuando se pone en marcha el primer proyecto ecoturístico transfronterizo, constituyéndose de manera formal, años más tarde, en la EBI. En 1998 se bota el primer barco hidrográfico para recorrer el tramo fronterizo de los Arribes del Duero/Douro Internacional, pudiendo los visitantes hacer uso de un crucero-aula medioambiental de 120 plazas dotado con laboratorio, cámaras de visión nocturna para observación de la fauna, así como una cubierta panorámica climatizada para los pasajeros. Las salidas se realizan junto a Miranda do Douro en el lado portugués de la Raya, con opciones de entre 1 y 3 horas de duración y todas ellas finalizan con una degustación de vinos de Oporto (Europarques, 2018).

Las actividades ecoturísticas de la EBI son las únicas de Castilla y León y Norte de Portugal reconocidas en la Unión Europea por la E.E.N. -European Ecoturism Network-, avaladas tempranamente con la Certificación de Turismo Familiar. También destacamos el proyecto de cooperación transfronteriza de la EBI, para la comercialización de productos de excelencia españoles y portugueses, seleccionados entre los artesanos y productores del Valle Internacional del Duero y su entorno, gestionados por Environmental Cruises y Douro Valley Shop, incentivando desde 2015 las compras de productos locales de calidad, ofrecidos a los turistas de los cruceros medioambientales. ${ }^{8}$

No existen registros publicados del número de usuarios que visitan la Estación Biológica Internacional del Duero (EBI), si bien, se tienen noticias de que en 2015 ascendieron a 70.000 turistas, de los cuales el 70 por ciento eligieron los buques hidrográficos como principal objeto de la visita (Geraldes et al., 2017: 376). ${ }^{9}$

Los resultados económicos tienen repercusión en varias localidades ribereñas, fundamentalmente Zamora, Valladolid, Braganza, Puebla de Sanabria y Miranda do Douro. Esta última, junto a Zamora serían las más beneficiadas, ya que alcanzaron en 2014 incrementos en el consumo gastronómico del 50 por ciento y en las compras un 22 por ciento, así como el aumento del resto de los servicios turísticos junto a las pernoctaciones, calculándose un gasto que superó los 2,7 millones de euros en servicios complementarios a los cruceros (Europarques, 2018).

7 www.losarribesdelduero.com/aldeadavila-de-la-ribera. www.dourovalley.eu.

8 www.miespacionatural.es/content/crucero-ambiental-de-arribes-del-duero. y http://www.duerodouro.org/.

9 www.duerodouro.org/. 


\subsection{Experiencias enoturísticas: vinos región Duero/Douro}

El vino ofrece nuevas oportunidades de negocio en numerosas comarcas (Martínez Puche y Morales Yago, 2016), donde el patrimonio y el viñedo generan otras formas de explotación turística en los espacios rurales y una mayor capacidad de atracción a nivel global desde lo local (Plaza Tabasco et al., 2017: 549)

El Duero desde su nacimiento en los Picos de Urbión hasta su desembocadura en Oporto, contempla los viñedos, a lo largo de un recorrido salpicado de regiones vitivinícolas, Ribera del Duero, Rueda, Toro, Arribes en territorio fronterizo y ya Douro, Vinho Verde y Porto en el lado portugués.

La propia historia enológica de Portugal nos remite a la Compañía General de Agricultura de las Viñas del Alto Douro, que en 1756 iniciara su recorrido impulsando la necesidad de mejores condiciones para la navegabilidad del Douro, en un largo camino hasta llegar al día de hoy (Martíns Pereira, 1991). Las visitas a las fincas vitivinícolas o quintas, promocionadas en Portugal a través de los cruceros, otorgan al río un papel estelar, como catalizador de una gran parte del atractivo turístico (Amorín et al., 2012a, Nuno Torres Senra, 2014), revalorizando el interior portugués con visitas a las quintas, degustación de catas y el ritual de la pisa (Lourenço-Gomes et al., 2015).

Las denominaciones de origen en torno al cauce del Duero se ubican a lo largo de unos $115 \mathrm{kms}$ de fértiles vegas, abarcando más de 100 pueblos de las provincias de Burgos, Segovia, Soria y Valladolid, identificadas sustancialmente con la actividad enoturística.

La Ruta del Vino Ribera del Duero es una de las más significativas, contabilizando en 2017 más de 15,3 millones de euros, un gasto medio de 40,54 euros y un número de 378.663 visitantes, lo que sitúa a esta ruta como la más rentable de las 27 certificadas en España (ACEVIN, 2018).

Por otro lado, la Ruta del Vino de Rueda se extiende a lo largo y ancho del margen izquierdo del Duero, por lo que sus vinos se elaboran en las proximidades del río, al igual que Toro y Arribes, si bien, la actividad turística se ciñe al turismo del vino, sin grandes conexiones con la actividad fluvial.

En el trazado portugués se reconocen las estrategias de marketing identificadas por Regional Tourism Entity of Porto and North of Portugal (ERTPNP, 2015), articulándose un plan turístico para las regiones del Norte de Portugal, un conjunto de propuestas en la que otorgan al turismo náutico una importancia capital, aludiendo al turismo de cruceros y visitas al Douro como eje central junto a la naturaleza y la enogastronomía, con repercusiones en los mercados de Portugal y España, siendo significativos los de Francia, Alemania, Reino Unido, EE.UU, Italia y Holanda (Rodrigues et al., 2018: 65-66).

La apuesta conjunta del turismo fluvial y la cultura enológica es especialmente importante en el Douro portugués beneficiando la actividad turística de la región de Porto, por ser el principal lugar de partida de los cruceros (Brambilla, 2015).

Peso da Régua es la capital de la comarca y su principal atractivo es el Museo del Vino, representando uno de los lugares básicos para visitar y comprender la historia y etnología de la región, reuniéndose de este modo turismo fluvial y cultura enológica (Amorín et al., 2012a). 
Siguiendo el cauce del Douro se encuentra Tua, donde se concentra una parte sustancial de las quintas de todo el río, en una tierra compleja y de difícil acceso para la labranza de las vides. El muelle de Pinhão es punto de atraque y permite visitar la quinta do Bomfim, otro de los lugares emblemáticos ligados al vino, llegando tras este punto a Provesende.

\section{TURISMO FLUVIAL EN EL DOURO: PRODUCTOS TURÍSTICOS Y CIFRAS DE MERCADO}

El Duero es navegable hasta Vegaterrón desde 1983, en el término municipal de Salamanca, cuando se concluyó la presa de Pocinho en territorio lusitano. El interés de la puesta en funcionamiento de las nuevas infraestructuras estuvo centrado, al principio, en el transporte de mercancías, desarrollando una de las zonas más atrasadas de Portugal (Trás-os-Montes), mejorando la conexión comercial con España (Calderón, 2017). Será en la década de los noventa en el siglo XX, en concreto en 1996, cuando esta presa favorezca el despegue del turismo, junto a la declaración de Patrimonio de la Humanidad del Centro Histórico de Oporto.

\subsection{La problemática de las fuentes y definición de los productos turísticos fluviales}

Las fuentes estadísticas en torno al tráfico de pasajeros merecen varias consideraciones previas. En primer lugar, se ha recabado información de la Administração dos Portos do Douro, Leixões e Viana do Castelo (APDL). La base de datos responde al proceso de constitución de APDL, que comienza su andadura el 1 de enero de 2015, cambiando ciertos criterios en las estadísticas que recogen la información de los cruceros fluviales. En esta fecha la empresa centenaria Port Authority-Administración de Duero y Leixões, SA.- se fusiona con Administración de Duero Puerto, Leixões y Viana do Castelo, SA, incorporando a la Administración de Viana do Castelo Porto, SA. (TSVC), buscando una mayor competitividad entre el puerto que atiende en Portugal a toda la Eurorregión y los puertos gallegos (APDL, 2018).

La serie histórica más extensa es la referida a los pasajeros en embarcaciones marítimo-turísticas censada desde 1994 y recogida por el Centro de Estudos de Geografia e Ordenamento do Territorio (CEGOT). Sin embargo, no existen registros que puedan consultarse de la empresa Europarques, encargada de gestionar la actividad crucerística en Arribes del Duero y el Lago de Sanabria.

En segundo lugar, es importante matizar los diversos conceptos que aparecen en las fuentes. Los cruceros de un día se definen como aquellos que se realizan en embarcaciones tradicionales o preparadas para el transporte de pasajeros fluviales (Amorín et al., 2012a:11), tienen los recorridos establecidos entre Oporto/Vila Nova de Gaia a Peso da Régua, Oporto a Pinhão (entre Peso da Régua e Barca d'Alva) con duraciones comprendidas entre las 7 y las 15 horas, siendo muy popular el retorno a Oporto en tren.

Los denominados cruceros nocturnos proponen una oferta, consistente en una cena acompañada de música tradicional, por tanto, su duración es más breve, aproximadamente de unas tres horas, realizándose los recorridos en el mismo tipo de embarcaciones que en los cruceros de un día (Amorím et al., 2012b: 58). 


\section{Mapa 2}

TRAZADO DEL RIO DOURO Y ESCLUSAS

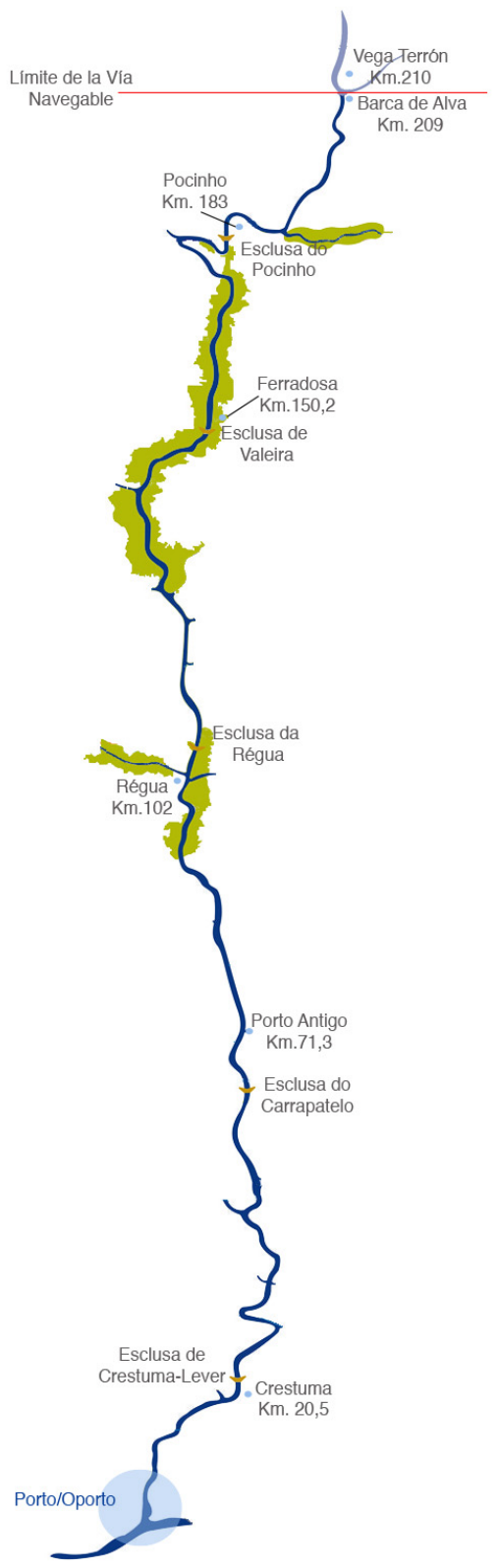

Fuente: Elaboración propia en base a la cartografía digital del Instituto Geográfico Nacional. 
Los cruceros en barco-hotel requieren de una inversión mayor, al necesitar unas infraestructuras acordes a una demanda más exigente. En algunos casos la oferta se centra en veleros que transportan pequeños grupos y puede originar, como en otros puntos de Europa, un turismo fluvial exclusivo y de lujo, que aporta mayor valor añadido al progreso económico del entorno. La duración del viaje varía entre los 5 y los 8 días según las webs turísticas más reconocidas. ${ }^{10}$

Finalmente, se hace referencia a los cruceros en la Albufeira, es decir, los que tienen lugar en la ría de Oporto, cuyo rasgo esencial es que tienen una corta duración, en torno a 1 hora. Los más típicos son los denominados de los "Seis Puentes", término que alude a sus recorridos, delimitados por estas infraestructuras vitales para Oporto.

\subsection{Operadores de cruceros y estacionalidad en la vía navegable del Douro (VND)}

La actividad turístico fluvial tiene su correlato en el aumento gradual de los operadores marítimo-turísticos que actúan en la vía navegable del Douro a lo largo del siglo XXI, si bien, ya en los años noventa del pasado siglo surgen las primeras empresas, que ponen en marcha pequeños trayectos turísticos (Carvalho Teles, 2012: 91-96).

\section{Figura 3}

\section{EVOLUCIÓN OPERADORES DE CRUCEROS (2001-2017) Y NÚMERO DE BARCO-HOTEL (2007-2017)}

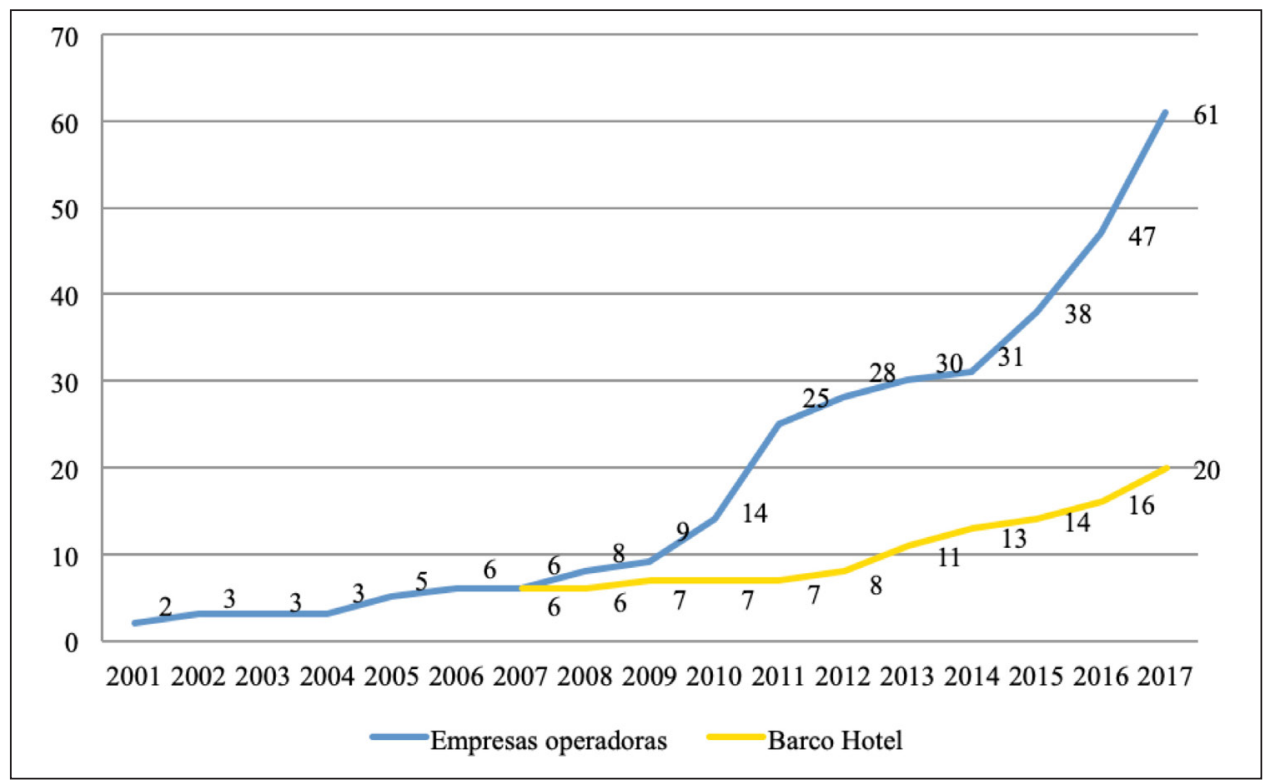

Fuente: Elaboración propia, datos APDL, 2019.

10 http://www.roteirododouro.com/cruzeiros-no-douro. Consultado 2/1/2018. 
Si en el año 2001 existían 2 operadores, en 2016 el número de empresas que gestionan los cruceros turísticos es de 47, y ya en 2017 la cifra se eleva a 61, lo que refleja el interés de este negocio. La creciente demanda ha impulsado la incorporación de 33 operadores en el último lustro, como se indica en la Figura 3, incrementando la flota de barco-hotel en cuatro nuevas unidades si observamos la cifra de 2017 respecto al año anterior.

Una de las empresas más potentes y pionera en el turismo fluvial en Portugal es Douro Azul, que opera desde su fundación en 1994, cuyo crecimiento camina paralelo al progreso del sector. En 2005 se ampliarán fronteras comerciales, con el fin de internacionalizar sus servicios se adquirieron 2 barcos-hotel, el "Invicta" y el "Alto Douro" con 40 y 24 camarotes respectivamente, realizando cruceros desde la ciudad de Oporto hasta la provincia de Salamanca, incluyendo visita y almuerzo en dicha ciudad, con una duración total de 8 días. En 2013, se inauguraron dos nuevos buques: el "AmaVida" y el "Queen Isabel", reforzando el liderazgo de la compañía, ofreciendo un producto turístico de gran valor añadido para el entorno, en el que se combina la vía navegable del Douro y el conocimiento de las ciudades y su gastronomía. ${ }^{11}$

El análisis de los programas ofertados por las compañías que operan en el Douro en 2015, destacan, además de Douro Azul y Croisieurope, otras corporaciones de interés como Viking, Uniworld, Amawater Ways, All Ways Cruises, Noble Caledonia and Vantage, mostrando la tipología de cruceros que programan por término medio los mencionados 8 días, con preferencia de rutas entre Oporto y Vila Nova de Gaia, observando la importancia de las principales infraestructuras y recursos que hacen posible estos recorridos (Guedes y Joukes, 2016: 94-97).

Otros operadores dignos de mención son Politurs y Douro Cruiser, ambos ofrecen viajes programados de una semana, con salida y llegada en Oporto y visitas de las principales ciudades a las que se llega a través del Douro, salvando las dificultades de la estructura mediante las esclusas, Entre-os-Ríos, Régua, Pinhao, Vega de Terrón y Barca d’Alva con opciones de visitar Salamanca y el recorrido inverso, con el referente de una riqueza patrimonial única vinculada al turismo fluvial. ${ }^{12}$

En estas valoraciones generales debemos tratar la estacionalidad que muestra el sector, pues es un capítulo a tener en cuenta en las campañas de promoción y un aspecto relacionado con el impacto que puede generar esta tipología turística. Los meses de mayor intensidad se sitúan entre mayo y octubre, siendo agosto el que aporta una cuota más alta, en concreto, en 2016 alcanzó un 18,70 por ciento, por tanto, el mes de más concentración de cruceros (APDL, 2018), particularmente porque el crucero río arriba sólo se hacen en un período determinado del año, generando riqueza y empleo temporal (Amorín et al., 2012a: 1065).

11 www.crucerosfluviales.es/douro-azul.naviera. Consultado 2/1/2018.

12 Ver en APDL lo concerniente a las compañías que operan en la VND. Consultado 5/4/2018. 


\subsection{Pasajeros y tipologías de cruceros en el río Douro}

Las cifras de pasajeros en buques de cruceros de corta duración, los denominados a nivel estadístico de 1 día, se muestran en la Figura 4 y realmente engloban recorridos turísticos con un número variable de horas. La escalada de pasajeros de cruceros fluviales hasta el año 2002 es intensa, superando los 100.000 pasajeros.

En los inicios del siglo XXI se observa un descenso acusado de los pasajeros embarcados, que es meramente coyuntural, que responde a la caída de uno de los puentes de Entre-os-Ríos, ${ }^{13}$ recuperándose posteriormente la actividad, creciendo de manera sostenida hasta el año 2005, donde se muestran ciertas oscilaciones, para finalmente comenzar un periodo de consolidación del sector, que en el último lustro asciende al 58 por ciento de pasajeros, si tomamos el último dato disponible y lo relacionamos con 2012, vislumbrándose un ascenso realmente importante.

\section{Figura 4 \\ SERIE HISTÓRICA PASAJEROS EMBARCADOS CRUCEROS DE 1 DÍA (1994-2017)}

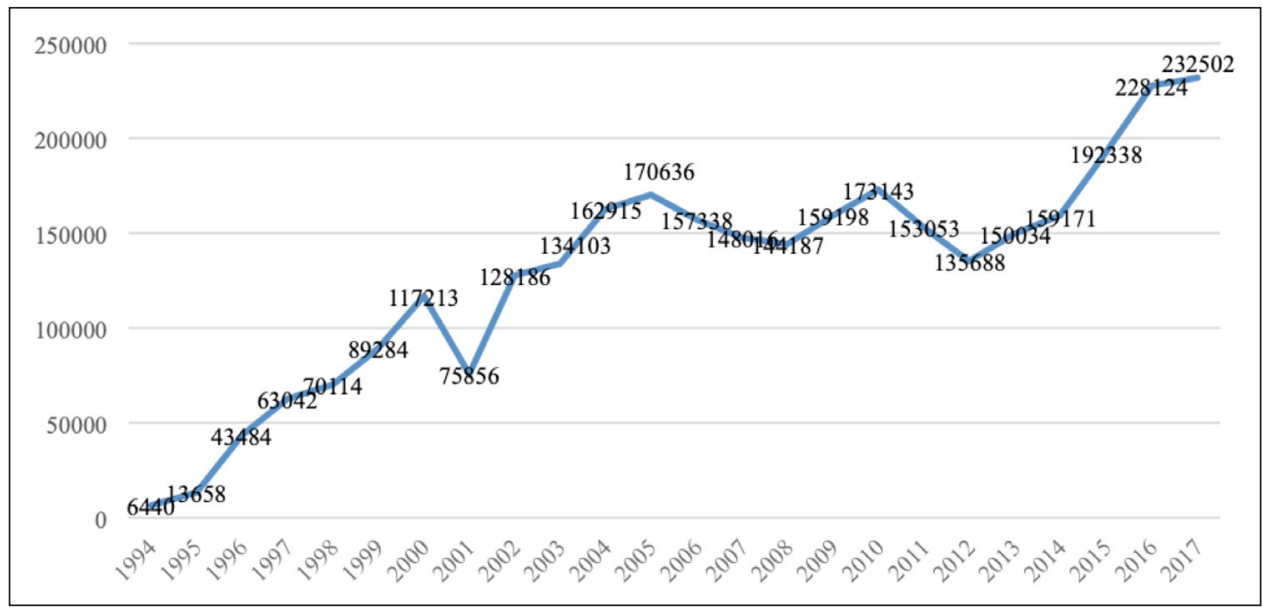

Fuente: Elaboración propia, datos IPTM (1994-2001) CEGOT y APDL (2002-2017).

Los cruceros nocturnos efectúan una ruta sencilla que los lleva desde los embarcaderos de las márgenes del Douro en Oporto, hasta el último de los Seis Puentes, incluyendo una cena con espectáculo musical para los pasajeros. Esta opción se ha consolidado en los últimos años, especialmente significativos en las ciudades ribereñas de Gaia y Oporto (Nunes et al., 2016). Los datos cubren la serie histórica comprendida entre los años 2006 y 2014 como se muestra en la Figura 5, ya que, a partir de este momento, las cifras de pasajeros de cruceros nocturnos se agregan a los de los cruceros por la "Albufeira",

13 www.age.ieg.csic.es/geografia_rural/Actividades\%20de\%20grupo/Documentos/.../1.2.pdf. Consultado $31 / 3 / 2018$. 
recorridos efectuados por embarcaciones del mismo tipo, presentándose a nivel estadístico conjuntamente. Una navegación particularmente importante en número, albergando diversas actividades deportivas. ${ }^{14}$

\section{Figura 5}

PASAJEROS DE CRUCEROS NOCTURNOS (2006-2014)

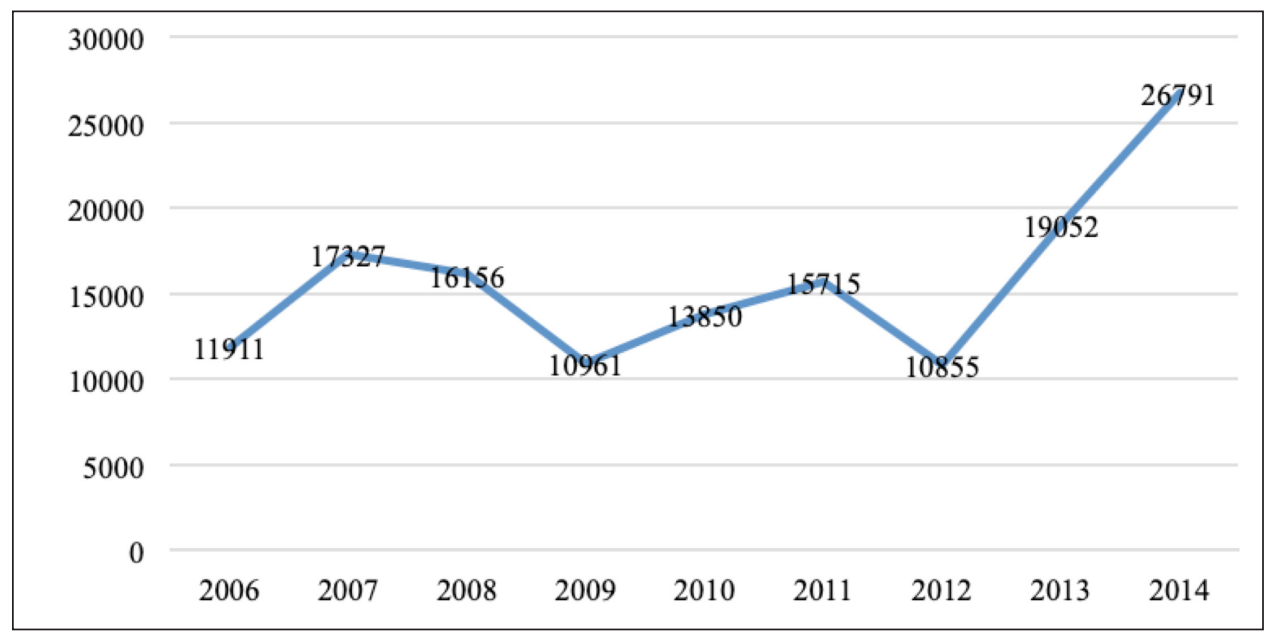

Fuente: Elaboración propia, datos APDL 2019.

Figura 6

PASAJEROS DE CRUCEROS ALBUFEIRA (2012-2017)

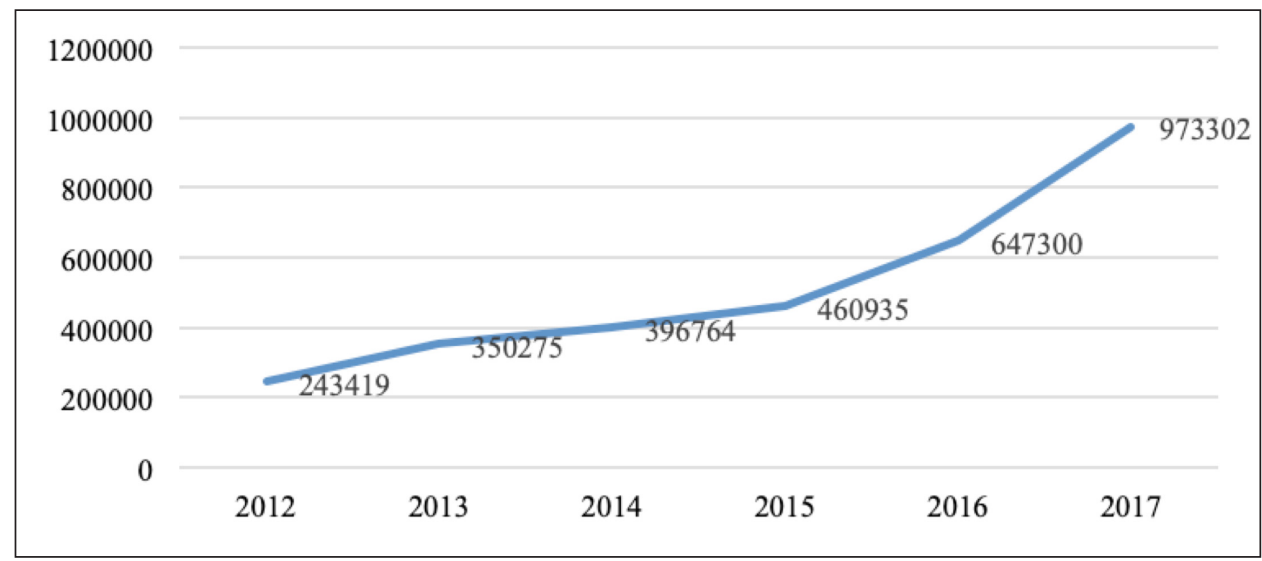

Fuente: Elaboración propia, datos APDL 2019.

14 Consultar otros detalles www.visitportugal.com. 
La Figura 6 muestra el grueso de la actividad crucerística, representado por los desplazamientos turísticos dentro de la "Albufeira", es decir la Ría de Oporto, cuyo rasgo esencial es que tienen una corta duración, en torno a los 50 minutos. Los más típicos son los conocidos de los "Seis Puentes". Los registros muestran que los cruceros de corta duración en los márgenes de la ciudad tienen una demanda considerable, representando una de las mejores vías de revitalización de espacios deprimidos de Portugal.

Llama la atención el último dato registrado en 2017, 973.302 pasajeros efectúan este recorrido, con un alza respecto al año anterior de un 76 por ciento, evidenciando este aumento tan significativo las repercusiones que tiene para el desarrollo económico del entorno.

\section{Figura 7 \\ EVOLUCIÓN PASAJEROS EN BARCO-HOTEL Y EN EMBARCACIONES DE RECREO (2007-2017)}

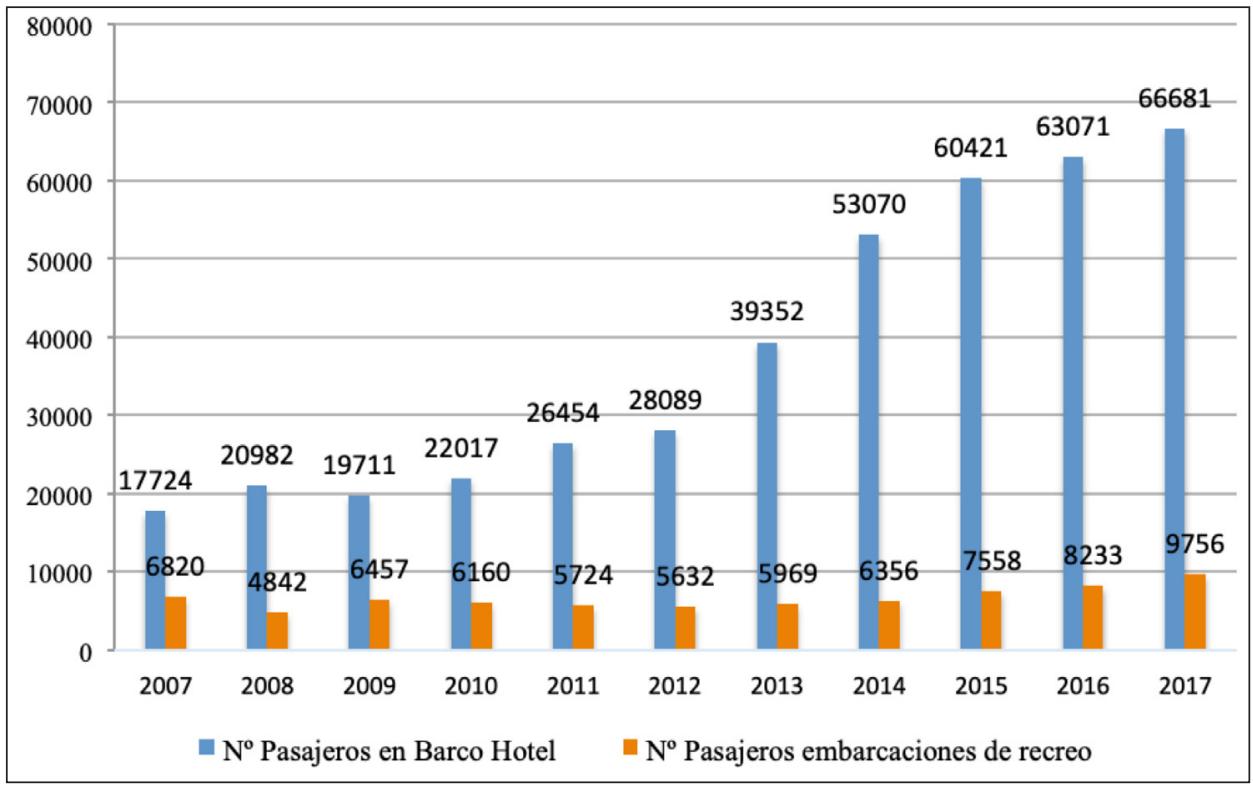

Fuente: Elaboración propia, datos APDL 2019.

La evolución del número de pasajeros en barco-hotel se dispone para la última década, como podemos comprobar en la Figura 7. Las travesías efectuadas entre las localidades de Oporto y Miranda do Douro se planifican para recorridos que oscilan entre 5 y 7 días. Los registros del último lustro permiten afirmar que el turismo fluvial se ha afianzado y presenta una evolución realmente significativa, constituyéndose esta modalidad en una oportunidad añadida para el propio turismo del vino (Rebelo et al., 2015).

El incremento de pasajeros en esta actividad es muy interesante ya que son los cruceros de varios días los que gozan de mayor impacto en la economía local. También permiten 
conocer de manera más profunda la cultura, los productos y la historia de las zonas por las que transitan los cruceros. En lo que concierne a la evolución de los pasajeros en barco-hotel, es significativo el crecimiento desde el 2013 en adelante y en lo que respecta a los pasajeros que utilizan embarcaciones de recreo, tras ciertas oscilaciones en los años finales, muestran una ligera tendencia al alza, que resaltamos en la medida que pueden suponer un impacto mayor, recogiendo los cruceros temáticos y experienciales, que transitan por la Vía Navegable do Douro, tan demandados hoy en día por los turistas de mayor poder adquisitivo.

El origen de los turistas queda reflejado en la Figura 8, y aunque es una serie de 2 años, los datos revelan que Portugal es el país emisor más importante cuya cuota de participación ha aumentado el 5,5 por ciento. La cuota de mercado del conjunto de países que tiene una representación se mantiene bastante estable, ya que su peso relativo en la cifra total no presenta cambios significativos.

La mayor parte de turistas proceden de Portugal y son dignos de mención el número de turistas de Estados Unidos y Francia, seguido de Inglaterra, países que además tienen la mayor participación relativa de turistas fluviales respecto al turismo en general, porcentaje que entre 2007 y 2014 ha pasado de un 0,3 por ciento al 0,8 por ciento y ya precisando por países destacar el alza de Luxemburgo y de Australia (Gouveia et al., 2017: 1681)

\section{Figura 8 \\ PASAJEROS DE CRUCEROS RÍO DOURO POR NACIONALIDADES (2015-2016)}

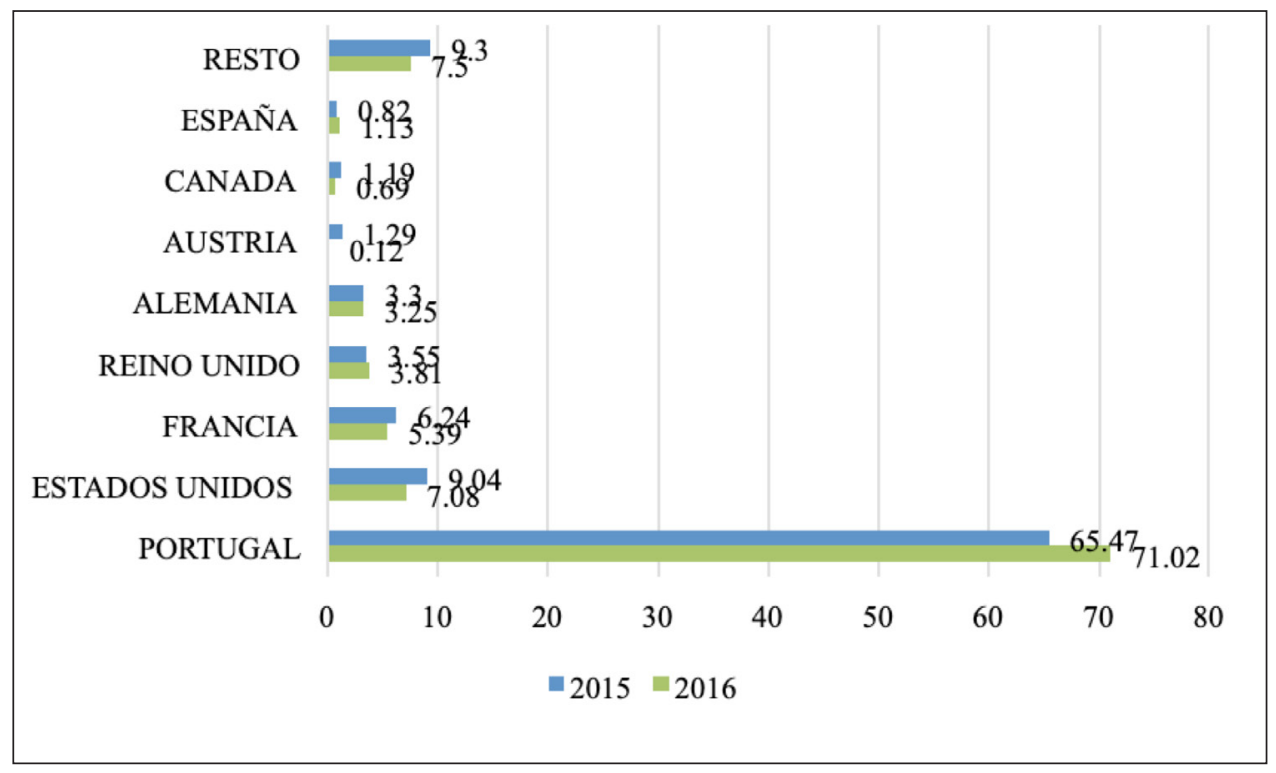

Fuente: Elaboración propia, datos APDL 2019. 
El caso de España es particular, pues entendemos que la proximidad haría factible, con las adecuadas campañas de promoción, unos resultados más favorables de participación, que, aunque crecientes, aún no representan una cifra interesante de mercado. Otras naciones con presencia son Alemania, Austria y Canadá, países que se sienten atraídos por el turismo fluvial, aunque en una proporción menor que los mencionados, respondiendo a las ventajas que representan el ser países de alta renta per cápita (Gouveia et al., 2017).

\section{CONCLUSIONES}

La cooperación transfronteriza ha seguido una trayectoria especialmente interesante en el desarrollo turístico de la Raya Ibérica y en los territorios colindantes, necesitados de políticas en común, que han sido defendidas en 2017 por el Foro Parlamentario Hispano Portugués, en la XXIX Cumbre Luso Española, definiendo aspectos económicos, medioambientales, energéticos y de infraestructuras que afectan a ambos países, acordando fórmulas conjuntas de actuación en el marco de la Unión Europea.

El denominado turismo sin fronteras se ve impulsado por el cauce fluvial Duero/ Douro, representando un nexo de unión, donde los "Caminos de la Espiritualidad", los Parques Naturales y el enoturismo, que tiene lugar entre Portugal y España, son elementos principales para el progreso.

Los pasos fronterizos generan sinergias "turísticas" relativas a actividades comerciales y culturales, cuyos núcleos urbanos se sitúan en "corredores" que la propia naturaleza ha ido conformando, en un territorio español que es, desde el punto de vista geográfico un enclave privilegiado y para el ámbito portugués la puerta de entrada a Europa.

La dotación de infraestructuras ha sido vital para la mejora de los destinos y las acciones emprendidas han supuesto el diseño de nuevas rutas e itinerarios, aprovechando el turismo fluvial esa naturaleza pródiga en flora y fauna en unos paisajes protegidos, que contribuyen hoy en día a la diversificación turística en torno a dos grandes pilares, de un lado Arte y Patrimonio y de otro, Cultura y Naturaleza.

Precisamente, las masas de agua y el relieve de las montañas y llanuras de la Región Duero/Douro han sido beneficiadas por la construcción de las distintas presas en el último cuarto del siglo XX, lo que ha permitido la transformación de los potenciales hídricos en actividad turística, fomentando el desarrollo de los destinos ribereños.

La investigación deja de manifiesto el interés de la riqueza patrimonial y la apuesta por el turismo fluvial, sobre la base de los principios que imperan hoy de sostenibilidad, desestacionalidad y desarrollo del territorio rural, en consonancia con las líneas políticas de actuación institucional y el apoyo de las iniciativas empresariales.

La declaración de la Meseta Ibérica como Reserva de la Biosfera Transfronteriza en 2015 y la declaración de Patrimonio de la Humanidad por UNESCO de Los Arribes, también han colaborado al progreso, al igual que ha sucedido en las ciudades que gozan de este reconocimiento, por el lado español Salamanca y por el portugués Oporto.

Los Arribes del Duero y el Douro Internacional han ido adquiriendo notoriedad turística en estos últimos años y al igual que el Lago de Sanabria han provisto unos escenarios idóneos, para que el turismo fluvial potencie la proyección turística a ambos lados de la frontera. 
Las rutas en general y en particular el senderismo, las actividades de multiaventuras y la fauna/flora son elementos comunes que vinculan el río a la naturaleza y dotan al entorno de una singularidad única y ya como propuesta de aula educativa, permite reforzar la formación de la sociedad en valores medioambientales, a través de los cruceros identificados con este adjetivo.

En este sentido, es importante destacar el papel de la Estación Biológica Internacional (EBI), pues sirve de punto de partida de otro de los recorridos turísticos, en donde la presa de Miranda do Douro representa el punto de arranque de actividades reconocidas a nivel internacional, gracias a su repercusión en el desarrollo económico de este espacio fronterizo, en la vanguardia de un turismo sostenible vinculando el río a su potencial capacidad turística.

Portugal y España elaboran vinos de gran calidad, generando un turismo del vino de gran interés, en el lado español concretado en las denominaciones de origen Ribera de Duero y Rueda. El Duero/Douro presenta una amplia oferta turística muy ligada a la producción de vinos de excelencia. Las rutas culturales enogastronómicas junto a otras actividades y servicios, pretenden crear valor añadido sobre los productos tradicionales de la cocina local, a través de un conjunto de experiencias, que permiten vivir de manera más intensa los cruceros donde el río y el "terroir" son pilares fundamentales.

En este capítulo entendemos que se debe seguir trabajando para favorecer el crecimiento conjunto del sector turístico, a fin de erigirse en recursos tan potentes como en el lado portugués, intensificando las campañas para afianzar la denominación de Arribes como producto vinícola, promocionándose, no sólo con la referencia de las quintas y el vino de Oporto como sucede preferentemente ahora.

La navegabilidad del Douro gracias a la construcción de las esclusas, ha dado paso a la estructuración de una oferta turística de gran impacto económico, reuniendo la naturaleza y la contemplación del Alto Douro Vinhaterio junto a múltiples actividades vinculadas a las quintas bodegueras, en donde la naturaleza, el recorrido fluvial del Douro y la riqueza enológica se funden en un entorno, que difícilmente se puede encontrar en otros parajes del territorio luso español.

La afluencia de turistas fluviales ha determinado el interés de los operadores de cruceros por aumentar su flota, favoreciendo el progreso de este segmento, especialmente en los cruceros que recorren la Albufeira, generando riqueza en las localidades ribereñas, con productos de gran aceptación para una demanda que es fundamentalmente del mercado local.

El binomio río y naturaleza provee los medios necesarios para el progreso de los cruceros temáticos, como se ha observado en las principales webs que ofertan estos productos. El maridaje entre la riqueza vitivinícola, las famosas quintas y el turismo de cruceros es una realidad creciente, que actúa como motor principal de unas visitas, que gozan en los últimos tiempos de un prestigio que trasciende la frontera luso española, observándose una positiva evolución de los pasajeros en barco-hotel y en los pasajeros embarcados de 1 día.

Significamos especialmente la búsqueda de los viajeros de mayor nivel adquisitivo que, junto a los cruceros temáticos, configuran un turismo experiencial en alza, en consonancia con los intereses del desarrollo del territorio rural y la imagen de unos destinos, que pueden y deben tener una gran proyección internacional, tal como sucede a nivel turístico en otros grandes ríos europeos. 
En cuanto a las nacionalidades destacar que es el mercado portugués el más significativo, seguido de EE.UU., Francia, Reino Unido y Alemania, con una cuota de participación reducida para el mercado español, por lo que entendemos que debían fomentarse un diseño más adecuado de las campañas de marketing por parte de las instituciones competentes, a ambos lados de la frontera, lo que redundaría en beneficios, planteados sobre la base de estudios de mercado que reconozcan los perfiles y preferencias de los potenciales clientes de la vecina España.

Realmente, las actividades propuestas en torno al río permiten compartir la historia de España y Portugal, a través de la riqueza artística y cultural de las distintas paradas que se realizan en pueblos y ciudades, en unos itinerarios fluviales donde las ciudades de Oporto y Salamanca son destinos obligatorios.

La proyección turística es reforzada por las actividades acuáticas y por el turismo de cruceros, convirtiéndose en una pieza clave en la revalorización de estos territorios, como ha sucedido en otros ámbitos internacionales, conformando un sector básico para un futuro más próspero en la Raya Ibérica y más allá de ella, a lo largo de todo el cauce del río Duero y Douro.

\section{BIBLIOGRAFÍA}

ACEVIN (2018): Análisis de la Demanda en las Rutas del Vino de España. Disponible en http://static.hosteltur.com/web/uploads/2016/02/Informe_ACEVIN.pdf.

ALMEIDA GARCÍA, F. (2012): "La política turística en España y Portugal”, Cuadernos de Turismo, $\mathrm{n}^{\mathrm{o}} 30$, pp. 9-34.

ALMEIDA MENDONÇA, J.P. (2012): "Esboço de um modelo de valorizaçâo turística para a regiâo fronteiriça do Douro/Duero", Rotur. Revista de Ocio y Turismo, no 5, pp. 81-95.

AMORIM, E., ANDRADE, C., FREDERICO, N. y UMBELINO, J. (2012a): "Los cruceros turísticos en el Douro y el segmento de vinos y gastronomía: Una propuesta de sustentabilidad sociocultural", Estudios y Perspectivas en Turismo, vol. 21 (4), pp. 1.050-1.107.

AMORIM, E., ANDRADE, C., TARLOW, P., MARIOTTI. V. y CARDONA, N. (2012b): Abordagem Multidisciplinar dos Cruzeiros Turísticos. Leiria, Portugual. Textiverso.

APDL - Administração dos Portos do Douro, Leixões e Viana do Castelo, S.A. (2019). Annual Vessel Traffic. Diponible en https://www.apdl.pt/.

BUCKLEY, R., WINN, T., LI, W., WINN, P. y ZHONG, L. (2018): "River Tourism in China", en Wang Y., Shakeela A., Kwek A. y Khoo-Lattimore C. (Eds.) Managing Asian Destinations. Perspectives on Asian Tourism. Springer, Singapore, pp. 231-240.

CALDERÓN VAZQUEZ, F.J. (2010): "La Raya luso-hispana, una frontera en transición", en Márquez, J.A. (Coord.), Actas del Congreso Internacional Cooperación Transfronteriza Andalucía-Algarve-Alentejo, Servicio de Publicaciones de la Universidad de Huelva, pp. 41-54.

CALDERÓN VÁZQUEZ, F.J. (2015): "Repasando la frontera hispano-portuguesa: Conflicto, interacción y cooperación transfronteriza", Estudios Fronterizos, vol. 16 (31), pp. 65-89. 
CALDERÓN VÁZQUEZ, F.J. (2017): “Fronteras intraeuropeas, desactivación fronteriza, cooperación transfronteriza e instituciones: El caso de La Raya Ibérica", Estudios Fronterizos, vol. 18 (36), pp. 78-101.

CAMPESINO FERNÁNDEZ, A.J. (2016): "Paisajes del agua y turismo fluvial en la Raya Ibérica”, en Vera, J. F.; Olcina, J.; Hernández, M. (Eds.). Paisaje, cultura territorial y vivencia de la Geografía. Libro homenaje al profesor Alfredo Morales Gil, Alicante, Universidad de Alicante, pp. 47-72.

CAMPESINO FERNÁNDEZ, A.J. (Coord.) (2013): Turismo de frontera (I). Edición de las I Jornada de Turismo de Frontera, Cáceres, 13-14 de diciembre, 2012. Red Ibérica de Entidades Fronterizas (RIET). Disponible en http://www.aecit.org/img/portada/ turismo\%20de\%20frontera.

CAMPESINO FERNÁNDEZ, A.J. (Dir.) (2014): Turismo de Frontera (II). Oferta y demanda turística en la Raya Ibérica, Edición de las II Jornadas de Turismo de Frontera, Guarda, 12-13 septiembre, 2013.

CAMPESINO, A.J. y JURADO, J.M. (Dirs.) (2014): Turismo de Frontera (III). Productos turísticos de la Raya Ibérica. Edición de la III Jornada de Turismo de Frontera, Huelva, 3-4 de abril, 2014, Huelva, Servicio de publicaciones Universidad de Huelva. Disponible en https://www.researchgate.net/publication.

CANTO GARCÍA, S.D. (2016): La cooperación transfronteriza en el Duero internacional. Tesis Doctoral. Universidad de León.

CARVALHO TELES, T.D. (2012): Turismo Fluvial no Douro: rio, camino de ontem atracçao de hoje. Master's Thesis.

CASTRO, J. P. y FERNANDES, P.O. (2007): "Parque Natural do Douro InternacionalArribes del Duero: orientações estratégicas", en XIII Congresso da Associação Portuguesa de Desenvolvimento Regional. Ponta Delgada.

CRISTÓVÃO, A. (2006): "Douro-Duero: em busca de caminhos para o desenvolvimento transfronteiriço", en Proceedings of the Congresso em Homenagem ao Douro/Duero e Seus Rios: Memória, Cultura e Porvir.

CRISTÓVÃO, A., TIBÉRIO, L. y ABREU, S. (2008): “Restauração, Turismo e valorização de produtos agro-alimentares locais: o caso do espaço transfronteiriço do Douro-Duero", PASOS: Revista de Turismo y Patrimonio Cultural, vol. 6 (2 especial), pp. 281-290.

CRUZ RUIZ, E., RUIZ ROMERO DE LA CRUZ, E. y ZAMARREÑO ARAMENDIA, G. (2018): "El rio Duero/Douro: puente turístico entre España y Portugal”, International Journal of Scientific Magnagement and Tourism, vol. 4 (2), pp. 219-233.

CRUZ-SAGREDO, D. (2010): Contrabandistas somos y en el descamino nos encontraremos. Valladolid, Gabinete de Iniciativas Transfronterizas.

DA COSTA PEREIRA, V. y PEREIRO, X. (2014): “Turismo transfronteiriço na Euroregião Galiza-Norte de Portugal”, Revista Turismo \& Desenvolvimento, n ${ }^{\circ} 21-22$, pp. 285-294.

DE JESUS PATO, M.L. (2016): “O Modesto Contributo do Turismo Rural no Douro, Portugal: um estudo baseado nos promotores e na oferta turística/La modesta contribución del turismo rural en la región del Douro, Portugal: un estudio basado en promotores y en la oferta turística”, Revista Turismo em Análise, vol. 27 (3), pp. 624-643. 
DE UÑA-ÁLVAREZ, E., CUQUEJO BELLO, M.C. y VILLARIÑO PÉREZ, M. (2017): "Valoración local del patrimonio natural para el desarrollo turístico en un territorio rural transfronterizo (Sierra del Larouco, Galicia-Norte de Portugal)", Papeles de Geografía, nº 63, pp. 181-194.

ELIZAINCÍN, A. (2006): "Los estudios sobre la frontera España/Portugal, enfoque histórico", Revista de Estudios Extremeños, vol. 62 (II), pp. 607-621.

FERNANDES DE SOUSA, C.A. (2013): Impacto no turismo da Região Demarcada do Alto Douro Vinhateiro, após a classificação de Património Mundial da Humanidade pe la UNESCO. Doctoral dissertation.

FIGUEROA DORREGO, P., PADIN FABEIRO, C., OTERO LIMA, A. y GALLEGO ORTIGUEIRA, D. (2014): "El termalismo como producto turístico en la Raya seca Luso Gallega”, en Campesino, A.J. y Jurado, J.M. (Dirs.). Turismo de Frontera (III). Productos turísticos de la Raya Ibérica. Edición de la III Jornada de Turismo de Frontera, Huelva, 3-4 de abril, 2014, Servicio de publicaciones, Universidad de Huelva, pp. 99-112.

GARCÍA GONZÁLEZ, L. (2004): “Agua y turismo. Nuevos usos de los recursos hídricos en la Península Ibérica, Enfoque integral”, Boletín de la Asociación de Geógrafos Españoles n ${ }^{\circ} 37$, pp. 239-255.

GERALDES, A. M., GUILLÉN OTERINO, A. y DE SALVADOR VELASCO, D. (2017): "Um cruzeiro eólico-solar pelo lago de Sanabria (NW Espanha): modelo inovador de gestão ecoturística para a interpretação ambiental em ecossistemas aquáticos dulçaquícolas", en III Congresso Ibero-Americano de Empreendedorismo, Energia, Ambiente e Tecnologia. Instituto Politécnico de Bragança.

GOUVEIA, S., REBELO, J., LOURENÇO-GOMES, L. y GUEDES, A. (2017): “International demand for the Douro (Portugal) river cruises: A gravity model approach", Tourism Economics, vol. 23 (8), pp. 1.679-1.686.

GUEDES, A., y JOUKES, V. (2016): "Hotel ships on the Douro River and their relationship with the terroir", en Wine and Tourism, Springer, Cham, pp. 87-105.

GUICHARD, F. LÓPEZ TRIGAL, L. y MARROU, L. (Coords.) (2000): Itinerarios transfronterizos en la Península Ibérica. Zamora, Fundación Rei Afonso Henriques.

GUILLÉN OTERINO, A. (2015): Lago de Sanabria presente y futuro de un ecosistema en desequilibrio. Estación Biológica internacional "Duero-Douro. Disponible en http:// www.duerodouro.org/area-de-investigacion/investigacion-lagode-sanabria/indice.

HERNÁNDEZ RAMÍREZ, J. (2017): “Turismo en la frontera: patrimonialización y cooperación transfronteriza en una periferia de la Unión Europea”, Etnográfica, Revista do Centro em Rede de Investigação em Antropologia, vol. 21 (2), pp. 385-409.

HORTELANO MíNGUEZ, L.A. (1996): "El Espacio Natural de Arribes del Duero”, en Primeras Jornadas de Turismo Rural en Arribes del Duero, pp. 131-151.

HORTELANO MÍNGUEZ, L.A. (2004): "El turismo en el valle del Duero/Douro. Una ruta temática jalonada de hitos naturales y culturales", en III Encontro Internacional: Relações Portugal-Espanha. O Vale do Douro no Âmbito das Regiões Europeias (Zamora, 10-11 de octubre de 2002).

HORTELANO MÍNGUEZ, L.A. (2013): “El turismo de la Raya Ibérica en la Cooperación Transfronteriza de primera generación (1992-2013): el caso de Castilla y León”, en 
Campesino Fernández, A.J. (Coord.). Turismo de Frontera (I). Rede Ibérica de Entidades Transfronteiriças (RIET), Vigo, pp. 131-139.

HORTELANO MÍNGUEZ, L.A. (2014a): “Dinámicas actuales en la «raya» de Castilla y León y Portugal: despoblación, atonía económica y desvertebración interna”, en Espaços de Fronteira, Territorios de Esperanza. Das Vulnerabilidades às Dinâmicas de Desenvolvimento, Iberografías $\mathrm{n}^{\circ} 27$, pp. 255-274.

HORTELANO MÍNGUEZ, L.A. (2014b): "Los productos turísticos en la «franja fronteriza» de Castilla y León con Portugal: la adaptación de los recursos y la interpretación territorial", en Turismo de Frontera (III). Productos turísticos de la Raya Ibérica, Huelva, Ediciones Universidad de Huelva, pp. 73-97.

HORTELANO MÍNGUEZ, L.A. (2015): "Patrimonio territorial y turismo en la «raya» de castilla y león: la atracción de los paisajes y la puesta en valor de los recursos", Cuadernos de Turismo, $\mathrm{n}^{\circ} 36$, pp. 247-268.

HORTELANO MÍNGUEZ, L.A. y MARTÍN JIMÉNEZ, M.I. (2017): “Territorio, patrimonio y turismo en la Raya de Castilla y León", Polígonos. Revista de Geografía, ${ }^{\circ}$ 29, pp. 165-189.

INÁCIO, A.I. (2010): “O destino enoturístico: desenvolvimento local e criação de valor”, COGITUR. Journal of Tourism Studies, vol. 3 (3), pp. 39-63.

IPTM (Instituto Portuário e dos Transportes Marítimos). (2013, 2014). Estatística da Via navegável do Douro (VND). Disponible en: http://www.douro.iptm.pt/_admin/upload/ estatisticas/7/8044952.

JORGE, F., BELO, M., LOSADA, N., SANTANA, O. y PEREIRO, X. (2017): “15 anos de Douro Património Mundial: sessão evocativa”, PASOS. Revista de Turismo y Patrimonio Cultural, v. 15 (3), pp. 751-754.

JURADO ALMONTE, J.M. y PAZOS GARCÍA, F.J. (2018): "La frontera como recurso turístico: posibilidades del bajo/baixo Guadiana”, Revista de Estudios Andaluces, $\mathrm{n}^{\circ}$ 35, pp. 1-34.

KASTENHOLZ, E., CARNEIRO, M.J., MARQUES, C.P. y LIMA, J. (2012): “Understanding and managing the rural tourism experience. The case of a historical village in Portugal", Tourism Management Perspectives, vol. 4, pp. 207-214.

KOVACIC, M., ZEKIC, A. y VIOLIC, A. (2017): “Analysis of Cruise Tourism on Croatian Rivers/Analiza kruzing turizma na rijekama Hrvatske", Nase More, vol. 64 (1), pp. 27-32.

LOIS GONZÁLEZ, R.C. y CARBALLO LOMBA, A. (2015): “La frontera hispano-lusa en la actualidad: una visión geográfica”, Revista de Historiografía (RevHisto), n 23 , pp. 191-214.

LÓPEZ TRIGAL, L. (2012): "Mudanzas en Portugal, en el contexto de la Península Ibérica", Polígonos. Revista de Geografía, n 17, pp. 157-163.

LÓPEZ TRIGAL, L. (2016): "Centralidades y nuevas actividades en la Raya Ibérica", Geopolítica (s), vol. 7 (2), pp. 181-200.

LOURENÇO-GOMES, L., PINTO, L.M. y REBELO, J. (2015): “Wine and cultural heritage. The experience of the Alto Douro Wine Region", Wine Economics and Policy, vol. 4 (2), pp. 78-87. 
MANERO MIGUEL, F. (2012): "La cooperación intermunicipal como estrategia de ordenación y desarrollo territorial en espacios transfronterizos: la Agrupación Europea de Cooperación Territorial Duero-Douro", Boletín de la Asociación de Geógrafos Españoles, $\mathrm{n}^{\circ}$ 58, pp. 249-272.

MANSVELT BECK, J. y HORTELANO MÍNGUEZ, L. A. (2016): “La apertura de la frontera: ¿nuevas identidades transfronterizas?”, Boletín de la Asociación de Geógrafos Españoles, $\mathrm{n}^{\circ}$ 72, pp. 271-284.

MARTÍN JIMÉNEZ, M. I. y HORTELANO MÍNGUEZ, L. A. (2017): “Cohesión y convergencia en la frontera de Castilla y León con Portugal (1986-2016): Población, economía y territorio", Anales de Geografía de la Universidad Complutense vol. 37 (1), pp. 183-216.

MARTÍNEZ PUCHE, A. y MORALES YAGO, F.J. (2016): “El vino como recurso turístico para el fomento del desarrollo local. Una oportunidad para las comarcas del Vinalopó (Alicante) y el altiplano Yecla-Jumilla (Murcia)", Cuadernos de Turismo, ${ }^{\circ}$ 38, pp. 267-300.

MARTÍNS PEREIRA, G. (1991): O Douro eo vinho do Porto: de Pombal a João Franco. Porto, Ediçoes Afrontamento.

MEDINA GARCÍA, E. (2006): “Orígenes históricos y ambigüedad de la frontera hispanolusa (La Raya)", Revista de Estudios Extremeños, vol. 62 (2), pp.713-723.

MOHD NASIR, F. y HANAFIAH, M. H. (2017): "River cruise impact towards local community: an exploratory factor analysis approach", Journal of Tourism, Hospitality y Culinary Arts, vol. 9 (2), pp. 175-188.

MORAL CUADRA, S., CAÑERO MORALES, P.M., JIMBER DEL RÍO, J.A. y ORGAZ AGÜERA, F. (2016): "Turismo fronterizo como motor de desarrollo de la frontera. Una revisión de la literatura”, International Journal of Scientific Managment Tourism, vol. 2 (2), pp. 249-265.

MORALES FERNÁNDEZ, E. y PÉREZ NARANJO, L. M. (2010): "El Turismo Religioso: Estudio del camino de Santiago", Gestión Turística, no 13, pp. 9-31.

NAVARRO, D. (2015): "Recursos turísticos y atractivos turísticos: conceptualización, clasificación y valoración”, Cuadernos de Turismo, n 35, pp. 335-357.

NUNES, A.N., LOURENÇO, L. y MEIRA, A.C. (2016): "Exploring spatial patterns and drivers of forest fires in Portugal (1980-2014)", Science of the Total Environment, vol. 573, pp. 1.190-1.202.

NUNES, A., OLIVEIRA MOREIRA, C., RODRIGUES PAIVA, I. y SOBRAL DA CUNHA, L. (2016): Territórios de Águal Water Territories. Coimbra, CEGOT, Centro de Estudos de Geografia e Ordenamento do Território, Universidade de Coimbra.

NUNO TORRES SENRA, J. (2014): O turismo fluvial como vetor de desenvolvimento turístico do Alto Douro Vinhateiro Património da Humanidade. Doctoral Dissertation.

OLIVEIRA MOREIRA, C. y PINTO DOS SANTOS, N. (2016): “Turismo fluvial em Portugal Continental: Oferta e potencialidades", en Territórios de Águal Water Territoires, pp. 255-271.

PALMERO PIÑEIRO, J.L. y PAZOS OTÓN, M.P. (2008): “La Eurorregión Galicia-Norte de Portugal: una aproximación a la movilidad en el contexto ibérico", Estudios Geográficos, $\mathrm{n}^{\circ} 264$, pp. 215-245. 
PARDELLAS, X., PADÍN, C., PEREIRO, X. y LAPA, V. (2003): “Turismo termal e desenvolvimento local: uma análise comparada do Ribeiro (Galiza) e do Alto Tâmega (Portugal)", Trabalho apresentado em IX Encontro Nacional da APDR, Actas do IX Encontro Nacional da APDR, Lisboa.

PEREIRA, G.M. (1991): O Douro eo vinho do Porto: de Pombal a João Franco.

PEREIRO, X. (2016): “Turistas portugueses na Galiza: imagens e relatos pós-experienciais”, en Trillo Santamaría, J.M. e Pires, I. (Comps.), Fronteras en la Investigación Peninsular: Temáticas y Enfoques Contemporáneos, Universidad de Santiago de Compostela, pp. 161-182.

PLAZA TABASCO, J.J., CAÑIZARES RUIZ, M.C. y RUIZ PULPÓN, Á.R. (2017): "Patrimonio, viñedo y turismo: recursos específicos para la innovación y el desarrollo territorial de Castilla-La Mancha", Cuadernos de Turismo, n 40, pp. 547-571.

PRETO, M.E. y ALENCOÃO, A.M. (2005): Patrimonio Geológico Transfronteiriço na Região do Douro. Roteiros. Vila Real, Universidade de Trás-os-Montes e Alto Douro.

REBELO, J. y CALDAS, J. (2013): “The Douro wine region: a cluster approach", Journal of Wine Research, vol. 24 (1), pp. 19-37.

REBELO, J., CALDAS, J.V. y GUEDES, A. (2014): “The Douro region: Wine and tourism”, en Bálo, B., Majer, P. y Váradi, G. (Eds.), Proceedings Xth International Terroir Congress 2014, v. 1, Tokaj-Eger: Corvinus University of Budapest, pp. 225-232.

REBELO, J., CALDAS, J. y GUEDES, A. (2015): “The Douro region: Wine and tourism. Almatourism Journal of Tourism”, Culture and Territorial Development, vol. 6 (11), pp. 75-90.

RIBEIRO COSTA, A. (2013): Destination branding: o papel dos stakeholders na gestão de uma marca-destino: o caso da marca Douro. Doctoral Dissertation.

RIBEIRO COSTA, A. y AZEVEDO, A.J. (2015): "Destination branding: o papel dos stakeholders na gestão da marca de destino-o caso da região do Douro (Portugal)", Revista Brasileira de Gestão e Desenvolvimento Regional, vol. 11 (1), pp. 182-202.

ROCHA MEDEIROS, E.J. (2009): A Cooperação Transfronteiriça na Raia Ibérica. Uma síntese geográfica dos impactes territoriais do INTERREG-A. Lisboa, Centro de Estudos Geográficos da Universidade de Lisboa (CEG).

RODRIGUES, V., BERNARDO, E. y DOMINGUEZ, C. (2018): "Public tourism framework in the Douro region tourism governance in perspective", Tourism and Hospitality International Journal, vol. 10 (1), pp. 55-75.

ROMERO, J. (2005): "El gobierno del territorio en España. Balance de iniciativas de coordinación y cooperación territorial”, Boletín de la Asociación de Geógrafos Españoles, $\mathrm{n}^{\circ} 39$, pp. 59-86.

ROSSOTTO IORIS, A.A. (2018): "Regional development, nature production and the techno-bureaucratic shortcut: the Douro River catchment in Portugal", Environmental Policy and Governance, vol. 18 (6), pp. 345-358.

RUIZ ROMERO DE LA CRUZ, E., CRUZ RUIZ, E. y ZAMARREÑO ARAMENDIA, G. (2017): ¿El origen lo es todo? Ayer y hoy de las denominaciones y marcas colectivas de garantía en el sector vinícola en España. Colección Papeles de Trabajo $n^{\circ} 42$, Facultad de Ciencias Económicas y Empresariales, Universidad de Málaga. 
SALCEDO HERNÁNDEZ, J. (2013): “Utilización de bases cartográficas digitales y posicionamiento GPS sencillo para inventarios de patrimonio en ordenación urbana y territorial", Turismo de Frontera (I) RIET, Vigo, pp. 167-183.

SÁNCHEZ MARTÍN, J.M. (2013): "SIG para la investigación turística en la Raya Ibérica", Turismo de Frontera (I) RIET, Vigo, pp. 155-166.

SÁNCHEZ RIVERO, M. (2014): "Mercados turísticos en el ámbito transfronterizo extremeño: los casos del Tajo Internacional y de Alqueva”, en Campesino, A.J. y Jurado, J.M. (Dirs) Turismo de Frontera (III): Productos turísticos en la Raya Ibérica, Huelva, Servicio de Publicaciones de la Universidad de Huelva, pp. 163-182.

SERENO, A. (2011): Ríos que nos separan, aguas que nos unen. Análisis jurídico de los Convenios Hispano-Lusos sobre aguas internacionales. Fundación Lex Nova.

SOTELO NAVALPOTRO, J.A., SOTELO PÉREZ, M. y SOTELO PÉREZ, I. (2016): "El «camino portugués» de Santiago, paisajes más paisanaje", en Vera, J.F., Olcina, Jorge y Hernández, M. (Eds.). Paisaje, cultura territorial y vivencia de la Geografía. Libro homenaje al profesor Alfredo Morales Gil, Alicante, Universidad de Alicante, pp. 381-414.

TRILLO SANTAMARÍA, J.M. (2010): Fronteras y regiones transfronterizas. El caso de Galicia-Norte de Portugal. Tesis doctoral. Universidad Carlos III de Madrid.

TRILLO SANTAMARÍA, J.M. y LOIS GONZÁLEZ, R. C. (2011): “La frontera como motivo de atracción: una breve mirada a las relaciones Galicia-Região Norte", Geopolítica (s), vol. 2 (1), pp. 109-134.

\section{Recursos electrónicos}

www.douro.apdl.

www.visitportoandnorth.travel/

www.zamoranatural.com/rio-douro-portugal/

www.turismosanabria.es/lago_sanabria.html.

www.patrimonionatural.org/espacios.../parque-natural-lago-de-sanabria-y-alrededores .

www.losarribesdelduero.com/aldeadavila-de-la-ribera.

www.vivelasarribes.es.

www.dourovalley.eu.

www.miespacionatural.es/content/crucero-ambiental-de-arribes-del-duero.

www.duerodouro.org/.

www.crucerosfluviales.es/douro-azul.naviera.

www.age.ieg.csic.es/geografia_rural/Actividades $\% 20 \mathrm{de} \% 20$ grupo/Documentos/.../1.2.pdf. 
